\author{
UNIVERSIDADE DE SÃO PAULO \\ FACULDADE DE ECONOMIA, ADMINISTRAÇÃO E CONTABILIDADE \\ DEPARTAMENTO DE ECONOMIA \\ PROGRAMA DE PÓS-GRADUAÇÃO EM ECONOMIA
}

\title{
Spillover effects of blacklisting policy in the Brazilian Amazon
}

Efeitos de transbordamento da Lista de Municípios Prioritários na Amazônia brasileira

Luíza Cardoso de Andrade Advisor: Prof. Dr. André Luis Squarize Chagas

São Paulo - Brasil

2016 
Prof. Dr. Marco Antonio Zago

Reitor da Universidade de São Paulo

Prof. Dr. Adalberto Américo Fischmann

Diretor da Faculdade de Economia, Administração e Contabilidade

Prof. Dr. Hélio Nogueira da Cruz

Chefe do Departamento de Economia

Prof. Dr. Márcio Issao Nakane

Coordenador do Programa de Pós-Graduação em Economia 


\title{
Spillover effects of blacklisting policy in the
}

\author{
Brazilian Amazon
}

Efeitos de transbordamento da Lista de Municípios Prioritários

na Amazônia brasileira

Dissertação apresentada ao Departamento de Economia da Faculdade de Economia, Administração e Contabilidade da Universidade de São Paulo como requisito parcial para a obtenção do título de Mestre em Ciências.

Orientador: Prof. Dr. André Luis Squarize Chagas

Versão corrigida

Versão original disponível na Biblioteca da Faculdade de Economia, Administração e Contabilidade

São Paulo - Brasil

2016 
FICHA CATALOGRÁFICA

Elaborada pela Seção de Processamento Técnico do SBD/FEA/USP

Andrade, Luíza Cardoso de

Spillover effects of blacklisting policy in the Brazilian Amazon /

Luíza Cardoso de Andrade. - São Paulo, 2016.

$83 \mathrm{p}$.

Dissertação (Mestrado) - Universidade de São Paulo, 2016.

Orientador: André Luis Squarize Chagas.

1. Economia ambiental 2. Econometria I. Universidade de São Paulo. Faculdade de Economia, Administração e Contabilidade. II. Título.

$$
\text { CDD }-333.7
$$


To my sister, Larissa, and my grandfather, Darcy 



\section{Acknowledgements}

I thank my family, especially my mother, for their love and support through these last three years; and those who became my family during these last three years, but were as loving and encouraging: Bia, Gui and Ana. All of this would have been a lot harder if it weren't for you guys. I'm also grateful to my roommates, Gato and Rato, and my step-roommates, Dantas and Rafa.

It was only possible to write this dissertation because I had a lot of help, though nobody is to blame for its faults except for me. I'm grateful to my advisor, André, whose patience and support have accompanied me since my first attempt at research in undergrad. I thank Alex Pfaff for receiving me at Duke University and giving me the opportunity to follow the activities of the University Program for Environmental Policy. I learned a lot from my time there, particularly from working with Alex and Erin Sills and having the privilege to listen to their discussions, as well as from taking part in the discussions of the Graduate Students Research Workshop. I thank the São Paulo Research Foundation (FAPESP) for funding through grants 2014/19332-6 and 2015/17942-4, and Pedro Ferraz from IBAMA for his help in accessing their data.

I'm grateful to Bruce, Ana, Flávio and all professors and researchers from NEREUS, especially professors Danilo Igliori and Ariaster Chimeli, for comments and suggestions through the different stages of this research's development. I'm also very grateful to all of my classmates for creating such a friendly and welcoming environment. I'll miss studying, debating and having coffee with you all.

Finally, I'm forever in debt to Laura, for always being there, no matter if it was to hold my hand in the many moments of anxiety or to revise this dissertation even though ancient Greek might be more comprehensible to her; and to Leo, who also endured more than his share of anxious moments and who possibly read this text even more times than I did. 



\section{Resumo}

Este trabalho avalia os efeitos da Lista de Municípios Prioritários, que indica os principais alvos de fiscalização da autoridade ambiental, sobre o desmatamento dos municípios na vizinhança dos listados. Argumenta-se que ter um vizinho listado causa uma variação exógena na presença das autoridades ambientais, e um estimador de diferença-em-diferenças é usado para determinar o impacto dessa presença sobre o desmatamento. Uma contribuição deste trabalho é acrescentar uma versão espacial do estimador para corrigir a dependência espacial na variável dependente. Nossos resultados mostram que o efeito líquido do tratamento é reduzir o desmatamento entre $19 \%$ e $23 \%$, e que esse efeito enfraquece à medida que a distância até o município prioritário aumenta.

Palavras-chaves: Desmatamento, spillovers, Amazônia, política ambiental 



\section{Abstract}

We analyse the effects of the Priority Municipalities List, that indicates the primary targets of environmental police monitoring, on deforestation of municipalities in the neighbourhood of the listed. We argue that being a neighbour to a priority municipality causes an exogenous variation in environmental authorities' presence, and use a differencein-differences estimator to determine the impact of such presence on deforestation. As an innovative feature, we introduce a spatial version of this estimator to correct spatial dependence. Our results show that the net effect of treatment is a decrease in deforestation of $19 \%$ to $23 \%$. Estimates also indicate that effects get weaker the greater the distance to the priority municipality.

Key-words: Deforestation, spillovers, Amazon, environmental policy 



\section{List of Figures}

Figure 1 - Mean number of environmental fines by group . . . . . . . . . . . . 28

Figure 2 - Credit granted for agricultural activities by group . . . . . . . . . . 30

Figure $3-$ Control and treatment groups . . . . . . . . . . . . . . 35

Figure $4-$ Deforestation and area by group . . . . . . . . . . . . . 38

Figure 5 - Amazon region political and biome limits . . . . . . . . . . . 43

Figure 6 - Blacklisted municipalities . . . . . . . . . . . . . 68

Figure 7 - Propensity score and entrance to the Priority Municipality List from

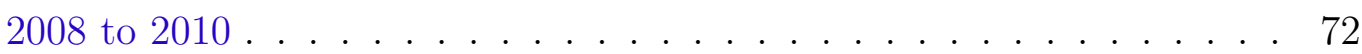

Figure 8 - Propensity score and entrance to the Priority Municipality List from

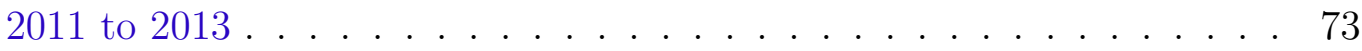

Figure 9 - Control and treatment groups under different neighbourhood criteria . 82

Figure 10 - Control and treatment groups under different neighbourhood criteria . 83 



\section{List of Tables}

Table 1 - Results from main specification . . . . . . . . . . . . . . . . 48

Table 2 - LM test for spatial specification . . . . . . . . . . . . . . 49

Table 3 - LM test for spatial specification in SLX model . . . . . . . . . . . . . 49

Table 4 - Results from Spatial model . . . . . . . . . . . . . . . . 50

Table 5 - Neighbourhood matrix test . . . . . . . . . . . . 51

Table 6 - Results with different dependent variables . . . . . . . . . . . . . 54

Table 7 - Results from placebo regressions . . . . . . . . . . . . . . 55

Table 8 - Results with different spatial matrices . . . . . . . . . . . . 56

Table 9 - Matching balance test . . . . . . . . . . . . . 57

Table 10 - Results with matched sample . . . . . . . . . . . . . . . 58

Table 11 - Propensity score results . . . . . . . . . . . . . . . . 71

Table 12 - Effect of listing on agricultural credit . . . . . . . . . . . . . . 79

Table 13 - Effect of listing on credit for cattle raising . . . . . . . . . . . . . . 79

Table 14 - Effect of listing on total credit . . . . . . . . . . . . . . . 80 



\section{Contents}

1 Introduction . . . . . . . . . . . . . . . . 19

2 The Priority Municipalities List $\ldots \ldots \ldots \ldots \ldots$

2.1 PPCDAm . . . . . . . . . . . . . . . . . . 23

2.2 Priority municipalities list $\ldots \ldots \ldots \ldots \ldots \ldots \ldots$

2.3 Listing criteria analysis $\ldots \ldots \ldots \ldots \ldots \ldots \ldots$

2.4 Mechanism discussion . . . . . . . . . . . . . . . 27

3 Theoretical framework $\ldots \ldots \ldots \ldots \ldots \ldots \ldots$

4 Empirical approach . . . . . . . . . . . . . . 35

4.1 Difference-in-differences estimator . . . . . . . . . . . . . . . . 35

$4.2 \quad$ Spatial econometrics . . . . . . . . . . . . . . . . . 39

4.3 Spatial difference-in-differences estimator . . . . . . . . . . . . . . 40

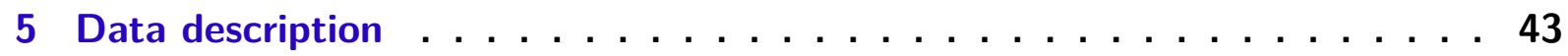

5.1 Municipalities . . . . . . . . . . . . . . . . . 43

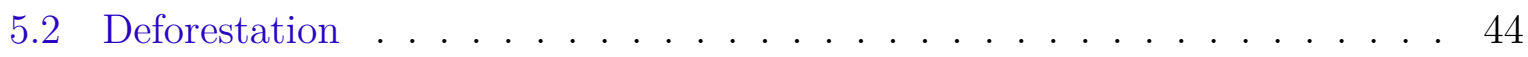

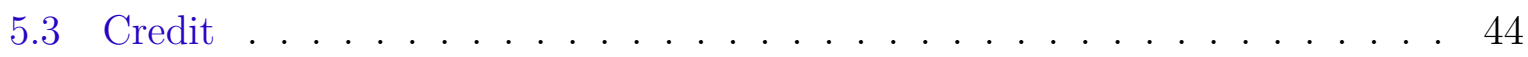

5.4 Environmental fines . . . . . . . . . . . . . . . . . . . . . . 45

5.5 Protection areas and indigenous reserves $\ldots \ldots \ldots \ldots \ldots$

5.6 Bolsa verde . . . . . . . . . . . . . . . . . . . . . . 45

5.7 Economic structure . . . . . . . . . . . . . . . . . . 46

6 Results . . . . . . . . . . . . . . . . . . . . 47

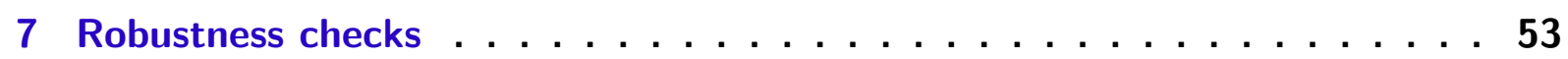

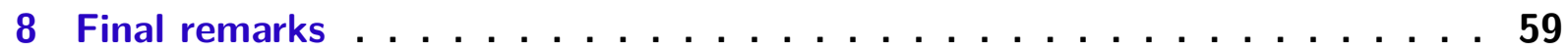

Bibliography . . . . . . . . . . . . . . 63

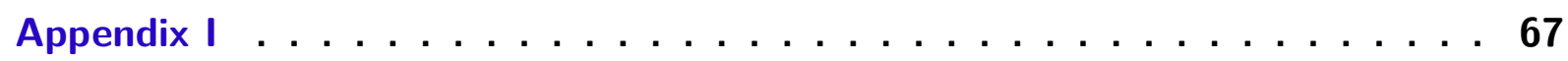

Appendix II . . . . . . . . . . . . . . . . . 69

Appendix III . . . . . . . . . . . . . . . . 75

Appendix IV . . . . . . . . . . . . . . . . 79 
Appendix V ........................ 81 


\section{Introduction}

From 2005 to 2012, deforestation in the Brazilian Amazon decreased by $75 \%$. This slowdown followed major changes in environmental policy. A growing literature investigating the new measures adopted since 2004 suggests that stricter command and control policies are the main cause for this reduction (ASSUNÇÃO; GANDOUR; ROCHA, 2012; ASSUNÇÃO; GANDOUR; ROCHA, 2013; MAIA et al., 2011; HARGRAVE; KISKATOS, 2013). Our goal is to evaluate the impact of a targeted monitoring policy, the Priority Municipalities List, implemented from 2008 to 2013. Unlike most of the literature, however, we are interested in spillover effects this policy might have had on non-listed subjects.

Land cover in the Amazon region has been monitored via satellite since 2004, and deforestation alerts are produced in real time, indicating to the environmental authorities the location of new clearings. Due to dispersed urban centers and lack of infrastructure in the Amazon, access to some regions and inspection of hot spots are costly. Therefore, a targeting strategy had to be developed to enhance inspection proceedings.

In 2008, a list of Priority Municipalities was released, comprising major deforesters. Although all municipalities in the Amazon are monitored via satellite, the main change introduced by this policy consisted on the inspection teams being allocated primarily to those in this blacklist. These municipalities are also subject to land property regularization proceedings, georeferencing of rural properties and credit constraints.

Some effort has already been made to evaluate the effectiveness of the blacklist. Arima et al. (2014), Assunção e Rocha (2014) and Cisneros, Zhou e Börner (2015) find significant reductions in deforestation on listed municipalities. While Assunção e Rocha (2014) identify command and control instruments as the main cause for the slowdown, Cisneros, Zhou e Börner (2015) argue that other institutional and reputation pressures were the decisive features.

Our focus, however, is to investigate if blacklisting has spillover effects, that is, if the Priority Municipality List, by focusing in one municipality, affects its non-targeted 
neighbours. We argue that blacklisting caused a shock in police presence on both listed municipalities and their non-listed neighbours. Once environmental police teams are located close to blacklisted municipalities, the probability of a priority municipality's neighbour being inspected is greater than that of a municipality that is far from environmental police's units, given the high transportation costs in the region. Therefore, we expect command and control policies to affect deforestation by reducing the expected value of engaging in criminal activities (BECKER, 1968; STIGLER, 1974).

Nevertheless, if deforestation gains are sufficiently high, it may be profitable for a closely monitored producer to relocate her activities to a less monitored municipality. In this case, unmonitored neighbours would experience an increase in deforestation. Thus, even though we expect producers in listed municipalities to reduce deforestation, the effect on their neighbours is uncertain. If the overall effect of blacklisting on untreated neighbours is to reduce deforestation, the policy's effectiveness might be underestimated. However, if blacklisting dislocates deforestation to neighbouring municipalities, not taking spillover effects into account overestimates the effects and misleads the policy's accountability.

We adopt difference-in-differences estimators to measure the List's effect on nonlisted neighbour's share of remaining forest cleared. As an innovative feature, we use a spatial econometrics methods to correct possible inefficiencies or biases caused by spatial autocorrelation. We adopt a spatial difference-in-differences estimator that, to our knowledge, has never been used to evaluate deforestation policies. Our results suggest the net effect of blacklisting on non-listed neighbours is an average decrease of $19 \%$ to $23 \%$ in the remaining forest area cleared yearly. This effect is reduced as we increase the cut-off distance that defines a neighbour. We also find that deforestation is a spatially dependent process, where both spatial lags of independent variables and unobserved, spatially correlated variables affect the outcome.

Our study draws upon a literature that extends the modelling of law enforcement to environmental monitoring (POLINSKY; SHAVELL, 1999; RUSSELL et al., 2013; GRAY; SHIMSHACK, 2011). Our findings relate particularly to those of Shimshack e Ward (2005), 
that investigates industrial plants' compliance to water pollution legislation as a response to sanctioning. They show that fines and other enforcement instruments have deterring impacts not only on sanctioned plants, but also on other plants subject to the same environmental authority.

Pfaff (1999), Chomitz e Thomas (2003), Hargrave e Kis-Katos (2013) and Robalino e Pfaff (2012) document the presence of spatial dependence on Amazon deforestation. They show that not only is accumulated deforestation very concentrated in a region known as Deforestation Arch, the decision to clear new plots is also affected by neighbouring conditions. Spatial spillovers of deforestation policies are also observed by Robalino e Pfaff (2012), Herrera (2015), Robalino (2007), Alix-Garcia, Shapiro e Sims (2012) and Pfaff et al. (2015).

This study is organized as follows. Chapter 2 discusses recent deforestation policies in the Brazilian Amazon, with special attention to the Priority Municipalities List and how it may affect land clearing decisions. Chapter 3 develops a theoretical model illustrating how spatial spillover may arise in this context. Chapter 4 presents our empirical approach. Chapter 5 describes the dataset used in our analysis. Chapter 6 presents our main findings. Chapter 7 presents some further robustness checks. Chapter 8 makes the final remarks. 



\section{The Priority Municipalities List}

The Amazon forest is the biggest tropical forest in the world, spreaded for around 5.5 million squared kilometers, $60 \%$ of which are in Brazilian territory. It provides environmental services such as biodiversity sheltering, carbon storage and rainfall regulation, apart from having water reservoirs that represent $20 \%$ of the world potable water. In the last decades, the world has paid particular attention to forests and to land use change in the context of climate change. ${ }^{1}$ According to the Brazilian Science Ministry, in 2005, land use change was the source of $57 \%$ of greenhouse emissions in Brazil. ${ }^{2}$ From 2012 to 2010, there was a 76\% drop in Brazil's land use change carbon emissions, most of it due to deforestation slowdown in the Amazon following a series of environmental policy changes.

\subsection{PPCDAm}

Since the mid-2000's, the Brazilian federal government has adopted a series of actions to inhibit deforestation in the Amazon, most of which are organized within the Plan for Prevention and Control of Deforestation in the Amazon Forest (PPCDAm). PPCDAm is the result of a large effort involving different levels of government and lays down the guidelines to coordinated action towards curbing deforestation. The Plan has three main basic lines: (i) land property ordination, (ii) command and control and (iii) promotion of sustainable activities. ${ }^{3}$ While the third focus was largely ignored, the first two encompassed a number of initiatives, and are pointed as reasons for the decrease in deforestation observed in the the last ten years (HARGRAVE; KIS-KATOS, 2013; ARIMA et al., 2014; CISNEROS; ZHOU; BÖRNER, 2015; INPE, 2013; ASSUNÇÃO; GANDOUR; ROCHA, 2012; ASSUNÇÃO; ROCHA, 2014; MAIA et al., 2011).

According to Maia et al. (2011), during the first phase of PPCDAm's implementation (2004-2006), the first basic line, land property ordination, was the most effective. These actions focused mainly on the creation of conservation units and Indian reserves. From

\footnotetext{
${ }^{1}$ IPCC (1996), Ambiente (2012).

${ }^{2}$ Informação (2013).

${ }^{3}$ Civil (2004)
} 
2004 to 2008, 25 million hectares of land were declared conservation units, and 10 million became Indian reserves. ${ }^{4}$ Land regularization was also sought after, since it was identified that most of deforestation occurred in plots occupied by producers with no land title.

The second basic line, consisting on command and control policies, is indicated by the same authors as the most effective during the second phase of the Plan (20072010). Until 2004, the Brazilian Institute for the Environment and Renewable Natural Resources (IBAMA), which acts as environmental police, based its inspection efforts on anonymous complaints. In that year, a system of satellite monitoring, DETER (Real-Time Deforestation Detection), was developed by the National Institute for Space Research (INPE). The INPE has been measuring yearly deforestation in Brazil via satellite since 1988, as part of the PRODES (Satellite Monitoring of Deforestation in the Legal Amazon) project. DETER, on the other hand, produces images of the Amazon in a more timely manner, issuing deforestation alerts every two weeks. Through the coordinated action of IBAMA and INPE, it is now possible to quickly identify new deforestation spots and monitor the region more efficiently, as reflected by the number of fines issued by IBAMA. ${ }^{5}$

Apart from the new monitoring system, IBAMA also hired new personnel and invested on training and on spreading new units of the agency across the Amazon. This actions notwithstanding, it is still a challenge to visit all of the sites indicated by DETER as deforestation hot spots (SOUSA, 2016). For this reason, the development of the second phase of the Plan aimed at better focusing IBAMA's activities, which, according to Maia et al. (2011), accounts for the success in reducing deforestation in the period. This strategy for targeting command and control policies, the Priority Municipalities List, is the focus of this project.

\subsection{Priority municipalities list}

In January 2008, through the Decree $n^{\circ}$ 6.321/07, the Ministry of Environment (MMA) became responsible for creating a list of priority municipalities, which are subject

\footnotetext{
${ }^{4}$ Assunção, Gandour e Rocha (2012), p. 9.

${ }^{5}$ Assunção, Gandour e Rocha (2012), p. 8.
} 
to more strict environmental regulation. These municipalities, that must be a part of the Amazon biome, should be selected according to three criteria: (i) total cleared area in the municipality; (ii) area cleared in the last three years; and (iii) increase in deforestation rate in at least three of the last five years.

Once in this list, municipalities should be monitored and supported by the federal government in the implementation of measures to reduce deforestation rates and promote sustainable activities. Rural properties in the priority municipalities are subject to registration in the National Institute for Colonization and Land Reform (INCRA), which might require georeferencing and land titles verification. The issuance of authorizations for land clearing in properties of medium to large size in these municipalities is also subject to georeferencing through the Rural-Agricultural Register (CAR), and agricultural credit offering is subject to the observance of environmental regulations in the properties. What is reportedly the most important feature of the policy, however, is that IBAMA's teams are primarily focused on these municipalities, which means that DETER alerts located in them have priority. ${ }^{6}$ Therefore, once a municipality is blacklisted, it is subject to more rigorous environmental inspection.

Every year, MMA must publish the list of Priority Municipalities, and announce the criteria to be unlisted, including, (i) having eighty percent of the municipality's private rural land monitored and in accordance with INCRA's technical criteria and (ii) maintaining deforestation under a limit established by IBAMA and announced yearly. ${ }^{7}$ Once a municipality is no longer in the list, it is classified as a municipality with deforestation under control and monitored.

In spite of reinforced monitoring efforts, environmental fines are seldom enforced. According to Souza-Rodrigues (2011), although the value of fines are extremely high when compared to average gross revenue, ${ }^{8}$ between 2005 and 2009 , only $0.6 \%$ of the total value of issued fines was actually paid. Assunção, Gandour e Rocha (2013) argue, however, that

\footnotetext{
${ }^{6}$ Assunção e Rocha (2014).

${ }^{7}$ The list of priority municipalities, by year of entrance, is in Appendix I. The listing criteria are is Appendix II, as well as their analysis.

${ }^{8}$ Fines range from US\$ 2,300 to US $\$ 23,000$ per hectare, compared to an average revenue of US\$ $120 /$ ha in 2006.
} 
these are not the only sanctions applied. Apart from being fined, producers caught illegally clearing the land are also subject to having their production seized and destroyed, their land embargoed and their machinery apprehended and auctioned.

Even though no official position as to the List's status has been taken, the last time a Decree listing criteria and municipalities was in 2013. That year, only the criteria to exit the list were published, and five municipalities were unlisted. Nonetheless, neither new additions nor new listing criteria were published, and interviews with local actors revealed that this is not the only instance of diminished federal attention to deforestation.

\subsection{Listing criteria analysis}

When trying to reconstruct the lists of Priority Municipalities published by the Ministry of Environment (MMA), we find the same difficulties described by Cisneros, Zhou e Börner (2015). Although there are official criteria to enter the lists, they don't seem to be either necessary or sufficient conditions to be listed.

Cisneros, Zhou e Börner (2015) suggest there's an unobserved weighting of the criteria by the authorities. We try to recover such weights using a logistic regression to estimate, for the years when the list was active, the probability of being listed as a function of that year's published criteria. In 2010, no municipalities were added to the list, so we did not include this year in our estimations. The results are shown in table 11 and illustrated in figures 7 and 8 . They indicate that the binding criteria vary from one year to the other. For 2009, none of the criteria were significant.

An analysis of the criteria distribution still leaves doubts on how some of the cutoff values were selected. As can be observed in the figures, some municipalities that satisfy the criteria to be listed are consistently left out of the list (the most prominent case is Itaituba), and municipalities with very low values for the variables supposed to constitute the criteria are listed (take, for example, Tapurah and Grajaú in 2011). This indicates that other criteria are also used, possibly political, which means blacklisting could be endogenous. 


\subsection{Mechanism discussion}

Works evaluating the effect of increased inspection efforts on deforestation usually take the number of fines as a proxy for environmental police presence (ASSUNÇÃO; GANDOUR; ROCHA, 2013; HARGRAVE; KIS-KATOS, 2013). We believe, however, that this may not be a good measure. As previously discussed, environmental law enforcement in the Brazilian Amazon works as follows: all municipalities are monitored via satellite, alerts are sent to environmental authorities every two weeks, police inspects some of the alerts, and inspections may or may not result in fines. Though we have data on deforestation alerts and number of fines issued, inspections are endogenous and depend on environmental police efforts, non-observable in the data. Consequently, the number of fines is also endogenous. We propose to use entrance in the Priority Municipality List as an exogenous source of variation in police presence on non-listed neighbours of listed municipalities.

We argue that the blacklisting policy caused a shock in environmental law enforcement on both listed municipalities and their non-listed neighbours. Every municipality in the Legal Amazon is subject to satellite monitoring, but inspection efforts by environmental police varies across the region. Transportation costs in the Amazon are high, due to the lack of infrastructure in the region and to high rainfall levels. Some locations can only be accessed by boat, and travel may take more than a week. Since the Priority Municipalities List created a new system for the allocation of police inspections, targeting primarily the listed municipalities, it also affected the cost of monitoring municipalities close to them. Once IBAMA's teams come to a listed municipality, the cost of inspecting its non-listed neighbours is lower than that of monitoring more distant municipalities. This causes a decrease in the expected value of deforestation, since the probability of being fined becomes higher.

This explanation depends on the assumption that the Priority Municipalities List causes a shift in environmental police presence. We consider this a plausible assumption because it is one of the announced measures. Nevertheless, it cannot be directly tested, 
since there is no available record of IBAMA inspections or of the value of total penalties imposed on violators. The number of fines, however flawed a measure of police presence, can give us some insight on that.

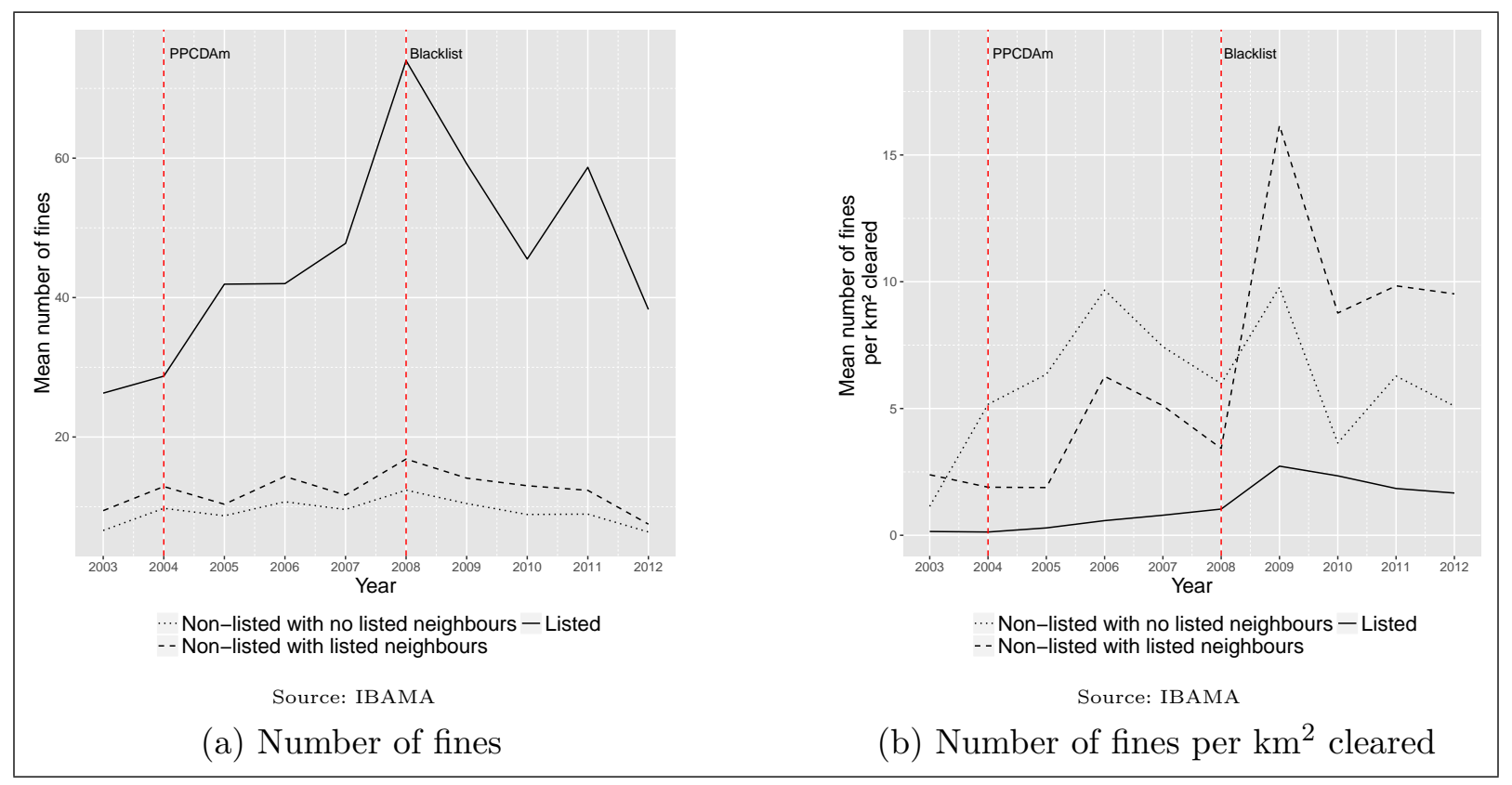

Figure 1 - Mean number of environmental fines by group

Figure 1a shows the evolution of the absolute number of fines in the region. In 2008, the first year the List was active, all groups faced an increase in the number of fines as compared to 2007, but this effect is stronger in listed municipalities and their neighbours than in the other municipalities in the biome. The downward trend in the number of fines after 2008 is probably related to deforestation slowdown, and absolute numbers are hard to compare due to the size of municipalities, as previously pointed. Therefore, we consider the number of fines to deforestation increment ratio as a proxy for monitoring stringency. This indicator is shown in figure 1b, which tells us a similar, but more interesting story: both listed municipalities and their non-listed neighbours present higher values for our stringency proxy after the List was created. Even though non-neighbours also show an initial raise in 2009, the average value for the whole period in these municipalities is actually lower than before 2008. Again, though we cannot affirm that we have causal evidence, these observations also seems to support our monitoring mechanism assumption. In fact, non-listed neighbours present a very similar stringency trend to non-neighbours, but they face a permanent shock after 2008, one that is even higher than that faced by 
listed municipalities.

Cisneros, Zhou e Börner (2015) attribute the effects of the blacklist to external pressure/support. However, unlike every other study of this policy, these authors don't even mention increased police presence as a measure taken in listed municipalities. They also fail to point actual examples of external pressure other than the Green Municipalities Program, which we take into account in our analysis. Furthermore, it is unclear how exactly these external pressures should affect the individual farmers' decision to clear new plots.

As an alternative mechanism, municipalities could respond to the possibility of entering the list and facing economic slowdown as consequence. If there is a response to the listing, such response would have to come from the municipality, an not individual farmers, through some sort of institutional change. ${ }^{9}$ That may be easier to observe. For such institutional effort to affect deforestation, a very well designed policy is necessary to induce individual farmers to cooperate and prevent free riding.

This economic threat mechanism assumes that the economy of listed municipalities suffers a slowdown as a consequence of their inclusion to the list. An economic slowdown could be a consequence of the greater scrutiny producers in listed municipalities are subject to regarding agricultural credit.

Figures $2 \mathrm{a}$ and $2 \mathrm{~b}$ display the mean amount of credit granted to municipalities in the Amazon biome. Given the similar trends among listed and non-listed, we conducted a simple difference-in-differences test to check for impacts of blacklisting on credit availability. Results indicate that, controlling for GDP and state and year fixed effects, agricultural credit did decrease on blacklisted municipalities, but credit for cattle raising experienced a raise and the effect on the sum of both, though negative, is not statistically significant. ${ }^{10}$

Assunção e Rocha (2014) highlight that the blacklist didn’t affect listed municipalities' economies. Still, we propose another way to test the validity of the proposed

\footnotetext{
${ }^{9}$ That is the case, for instance, of Programa Municípios Verdes, which was first implemented in 2013. This program is an initiative of Pará's state government and consists in creating a pact with local actors to reduce deforestation so that municipalities can either get out of the List faster or avoid being listed at all.

${ }^{10}$ Results are in tables 12,13 and 14 of Appendix IV.
} 


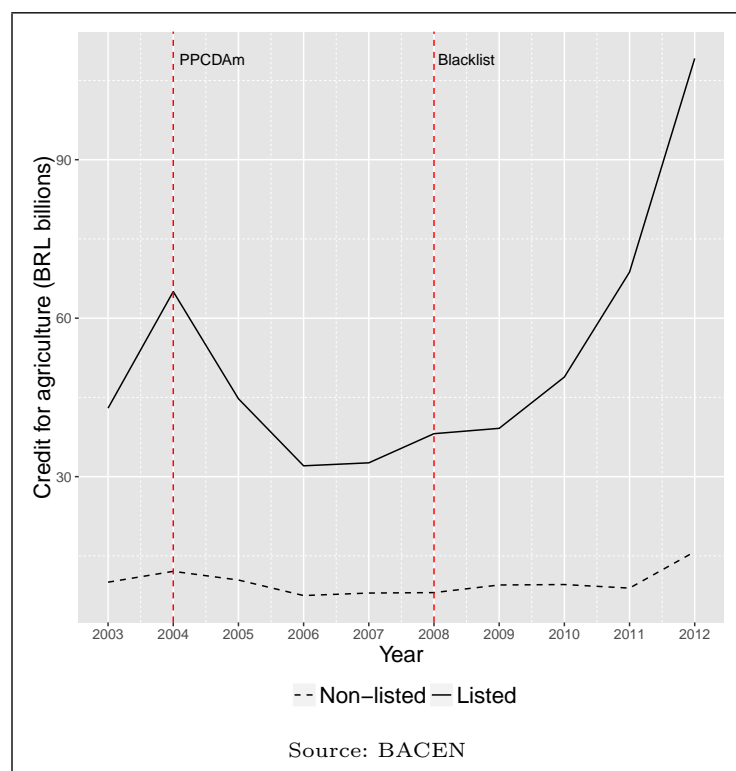

(a) Agricultural credit granted

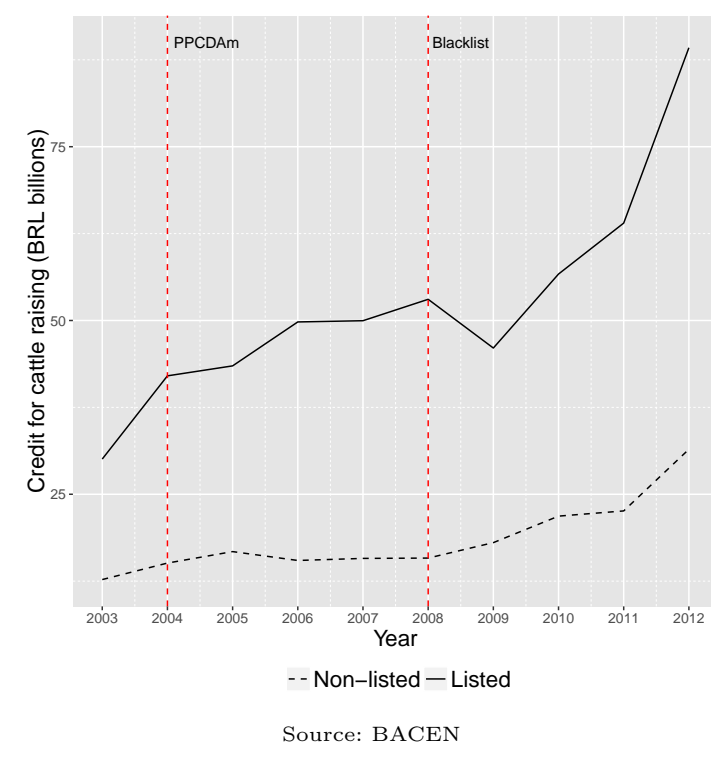

(b) Cattle raising credit granted Source: BACEN

Figure 2 - Credit granted for agricultural activities by group

mechanism: we use matching techniques to create control and treatment groups with equal chances of being listed. Once we match municipalities on the probability of being listed, the policy's observed effect should be attributed to other causes, more specifically, following our model, to increased monitoring. 


\section{Theoretical framework}

The decision to clear a forested area can be modeled as part of the land use decision, which is typically characterized by a model of porftfolio composition (YOUNG, 1997). We assume there are two alternative and concurrent land use possibilities: agricultural production and forest conservation. The model described below is based on Pfaff (1999).

Let $i$ be a producer that disposes of a capital $Q$ to invest in a plot of land, which will be spent in sunk costs such as buying/renting the land and machinery. In any given period $t$, producer $i$ in municipality $j$ chooses land use $l$, either preserving the standing forest or clearing it, by solving the following problem:

$$
\begin{aligned}
\underset{l \in\{\text { cleared,forest }\}}{\operatorname{Max}} \pi_{i j t}^{l}= & P_{i j t}^{l} Y_{t}^{l}\left(x_{i j t}\right)-C T_{t}^{l}\left(z_{i j t}\right) \\
\text { s.t. } & \left\{\begin{array}{l}
x_{i j t}=x_{i j t}(l) \\
z_{i j t}=z_{i j t}(l)
\end{array}\right.
\end{aligned}
$$

where $P_{j t}$ is the price of agricultural production; $Y_{t}^{l}$ is the output as function of a input vector $x_{i j t}$; and $C T_{t}^{l}$ is the total cost of production as a function of a vector $z_{i j t}$ that includes the price of inputs and transportation, taxes and licensing costs.

Land use decision can be described by

$$
\operatorname{Max}_{l \in\{\text { cleared,forest }\}} V_{i j t}^{l}=\operatorname{Max}_{l \in\{\text { cleared,forest }\}} \pi_{i j t}^{l}
$$

Therefore, the producer will decide to clear the plot if the profit with agricultural activity is greater than the profit from exploring the standing forest:

$$
l_{i j t}=\text { cleared if and only if, } V_{i j t}^{c}>V_{i j t}^{f}
$$

Law enforcement literature, on the other hand, models the decision to break the law as a function of the following variables (POLINSKY; SHAVELL, 1999): $g$, the gain from illegal activity; $\pi^{e}$, the expected probability of being caught; and $L$, the loss caused by the punishment. A risk-neutral agent decides to break the law if and only if his gain is 
greater than the expected loss from punishment, i.e., if

$$
g \geq \pi^{e} L
$$

We assume, for simplicity, that forested land is not used, that is, no revenue is gained from selling forest products and the land owner does not incur in any sort of maintenance cost, so that

$$
V_{i j t}^{f}=0, \forall i, j, t
$$

We Consider, in addition, that different plot owners have different perceptions and/or face different probabilities of being caught. Finally, supposing all deforestation is prohibited, when a firm is caught clearing land, her production will be seized and the land, embargoed, which means there will be no revenue. Apart from that, the instruments and machinery will be seized and fines may be applied, so the firm will suffer an additional loss of $L_{i j t}$, In this case, the gain with deforestation, that is, with buying a plot of forest land, clearing it, and then using it for production purposes, $V_{i j t}^{d}$, is different from the gain from a previously cleared plot $V_{i j t}^{c}$, and is given by

$$
V_{i j t}^{d}=\left(1-\pi_{i j t}^{e}\right) V_{i j t}^{c}-\pi_{i j t}^{e} L_{i j t}
$$

With these changes, we can model producer $i$ 's decision to deforest a land plot in municipality $j$ in time $t$ as

$$
d_{i j t}=1\left[\left(1-\pi_{i j t}^{e}\right) V_{i j t}^{c}-\pi_{i j t}^{e} L_{i j t}>0\right] .
$$

Total deforested area in municipality $j$ is then given by

$$
D_{j t}=\sum_{\in i} 1\left[\left(1-\pi_{i t}\right) V_{i j t}^{c}-\pi_{i t} L_{i j t}>0\right] \operatorname{area}_{i j} .
$$

We will now extend this framework to allow for the possibility that the agent may move from municipality $j$ to a municipality $k$, located at a distance $d_{k, j}$ from $j$. The producer is faced now with the decision to choose (i) if she will stay in municipality $j$ or move to $k$; (ii) if she will clear the plot or not. We will assume that moving the production means incurring in dislocation costs $\phi\left(d_{k, j}\right)>0$, since sunk costs are not entirely mobile 
(rents are non-refundable, transporting equipment is costly, etc.). Once forest land does not generate any revenue and dislocation costs are positive, the agent will never choose to move if not to clear the land. On the other hand, moving will only be profitable if

$$
\left(1-\pi_{i k t}^{e}\right) V_{i k t}^{c}-\pi_{i k t}^{e} L_{k j t}-\phi\left(d_{k, j}\right)>\left(1-\pi_{i j t}^{e}\right) V_{i j t}^{c}-\pi_{i j t}^{e} L_{i j t}
$$

Adding a few assumptions will make the analysis easier, though they are not strictly necessary. First, suppose that the value of fines is irrelevant as compared to $Q$, so that the loss with sanctions is due to instruments and machinery apprehension ${ }^{1}$. Additionally, assume that, given the investment $Q$, the maximum profit from land clearing is the same in any municipality. This might happen if prices and land productivity are equal in both municipalities.In the appendix we develop the calculation involved in this model more thoroughly and include a complete version, without the assumptions just stated. Although both assumptions can be easily relaxed, they make the interpretation of our results more straight forward.

These assumptions give us

$$
\begin{gathered}
L_{i j t}=L_{i k t}=L_{t}\left(Q_{i}\right)=L_{i t} \\
V_{i j t}^{c}=V_{i k t}^{c}=V_{t}^{c}\left(Q_{i}, Z\right)=V_{i t}^{c}
\end{gathered}
$$

Then equation (3.4) can be written as

$$
\left(\pi_{i j t}^{e}-\pi_{i k t}^{e}\right)\left(V_{i t}^{c}+L_{i t}\right)>\phi\left(d_{k, j}\right)
$$

When the expected probability of being punished increases, the expected gains decrease and the expected losses increase. Therefore, the higher the difference in the expected probability of being punished between the two municipalities, the more an agent will be willing to pay to move from one municipality to another.

Thus, combining conditions (3.2) and (3.7), we have that the decision to clear the

\footnotetext{
${ }^{1}$ This assumption is not as unrealistic as it might seem. Indeed, evidence shows that fines are rarely paid and other sanctions are responsible for the costs of being caught (SOUZA-RODRIGUES, 2011; ASSUNÇÃO; GANDOUR; ROCHA, 2013).
} 
plot in municipality $j$ is described as

$$
d_{i j t}=1\left[\left(1-\pi_{i j t}^{e}\right) V_{i t}^{c}>\pi_{i j t}^{e} L_{i j t}\right] \times 1\left[\left(\pi_{i j t}^{e}-\pi_{i k t}^{e}\right)\left(V_{i t}^{c}+L_{i t}\right) \geq \phi\left(d_{k, j}\right)\right]
$$

while the decision to move and clear a plot in municipality $k$ is described as

$$
d_{i k t}=1\left[\left(1-\pi_{i k t}^{e}\right) V_{i t}^{c}>\pi_{i k t}^{e} L_{i j t}\right] \times\left\{1-1\left[\left(\pi_{i j t}^{e}-\pi_{i k t}^{e}\right)\left(V_{i t}^{c}+L_{i t}\right) \geq \phi\left(d_{k, j}\right)\right]\right\} .
$$

Thus, the difference between the expected probabilities of being caught in municipalities $j$ and $k, p \pi_{i j t}^{e}-\pi_{i k t}^{e}$, affects the location of deforestation. Now, lets say municipality $j$ was treated in period 1 , so that the expected probability of being punished in this period is greater than that of the previous period, that is, $\pi_{i j 1}^{e}>\pi_{i j 0}^{e}$, and municipality $k$ was not. The spillover effect on deforestation in $k$ caused by treating $j$ depends on how $\pi_{i k t}^{e}$ is affected. If $\pi_{i k t}^{e}$ decreases, because agents expect monitoring to focus exclusively on treated municipalities, deforestation will likely increase in municipality $k$, both because production will became profitable for agents on $k$ who did not produce previously and because moving the production to $k$ may became more profitable for producers previously located in municipality $j$. If $\pi_{i k t}^{e}$ is left unchanged (or increases very little), then it may still be profitable for some producers in $j$, namely those with high $V_{i t}$, to move to $k$, which induces an increase in deforestation in the untreated municipality $k$. Finally, if $\pi_{i k t}^{e}$ increases enough, because agents expect monitoring efforts to cross municipalities' borders, then not only deforestation will not migrate from municipality $j$ to municipality $k$, it will also decrease in municipality $k$, since it will no longer be profitable for agents previously located in $k$ to clear the land. 


\section{Empirical approach}

A municipality does not choose its own location, and the agents (federal government, mayors, farmers) cannot choose the neighbours of listed municipalities. Therefore, though there is potentially endogeneity in the Priority Municipality list, being a neighbour to a priority municipality is random. With this idea in mind, we build our control and treatment groups: we consider non-listed municipalities with listed neighbours as being treated, and non-listed municipalities with no listed neighbours as control group. Because the literature suggests that deforestation is a spatially dependent process (PFAFF, 1999; CHOMITZ; THOMAS, 2003; HARGRAVE; KIS-KATOS, 2013; ROBALINO; PFAFF, 2012), which is intuitive considering the spatial distribution of treated and control municipalities shown in figure 3, we test for spatial correlation and use a spatial version of our main estimator to confirm our results.

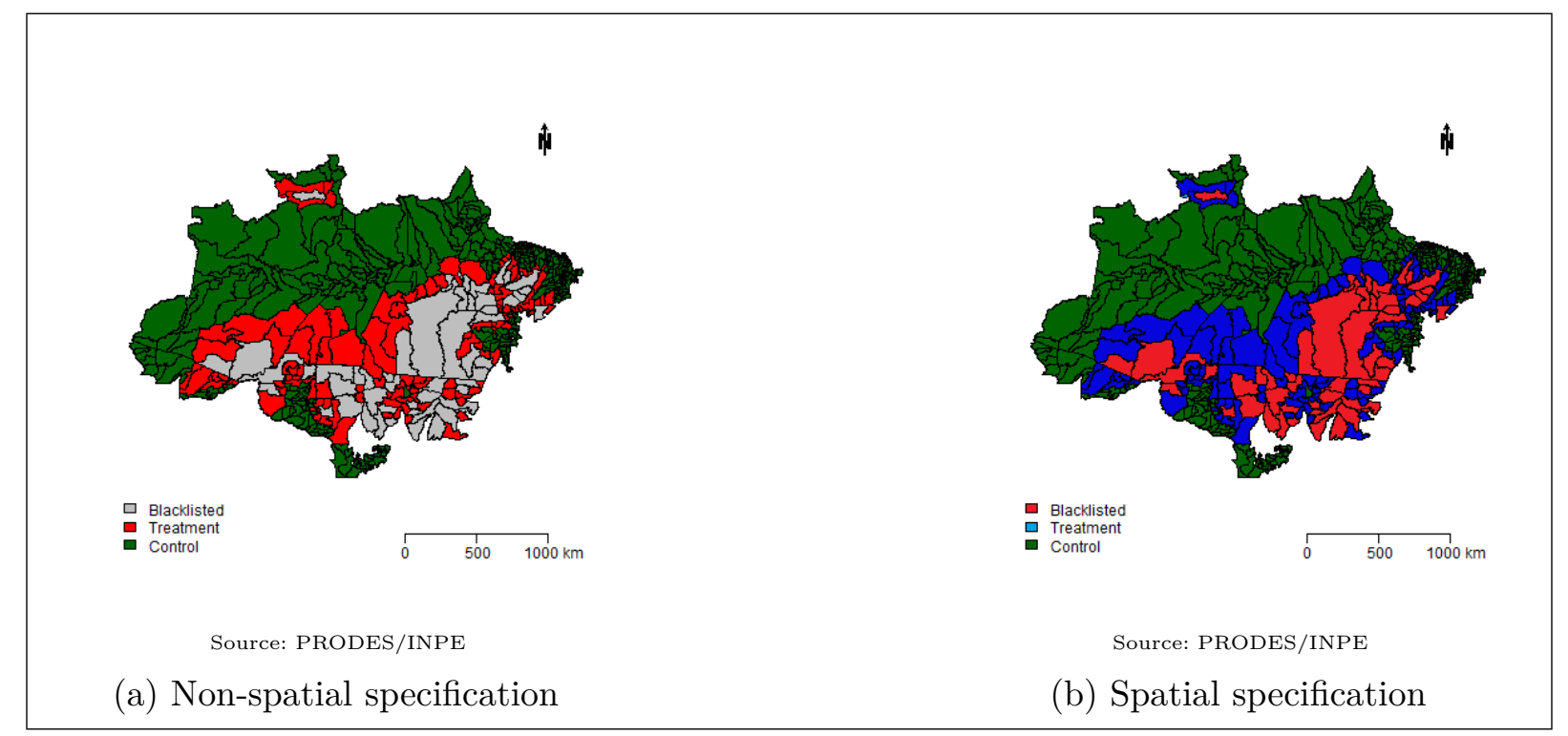

Figure 3 - Control and treatment groups

\subsection{Difference-in-differences estimator}

We begin by evaluating the effect of blacklisting in non-listed neighbours through a simple difference-in-differences estimator. One advantage of using this estimator is that it controls for unobserved time invariant variables. This is particularly useful, since local characteristics that influence agricultural potential may not be easily measured. However, 
it also means we cannot include time-invariant controls that could be of interest, such as total municipality area.

Let $y_{i t}$ be the deforestation in municipality $i$ and year $t ; x_{i t}$ a vector of observable characteristics; trat $_{i t}$ a a treatment dummy trat $_{i t}=1$ if municipality $i$ was treated in year $t$ and trat $_{i t}=0$ otherwise); and trat $_{i}$ a dummy indicating if municipality $i$ is in the treatment group, i.e., if it was ever treated. The equation to be estimated through ordinary least squares is

$$
y_{i t}=\alpha+x_{i t}^{\prime} \beta+\gamma \text { trat }_{i}+\delta \text { trat }_{i t}+u_{i t}
$$

Before the treatment,

$$
\begin{aligned}
& y_{i t, 1}^{b}=\alpha+\gamma+x_{i t}^{\prime} \beta+u_{i t} \\
& y_{i t, 0}^{b}=\alpha+x_{i t}^{\prime} \beta+u_{i t},
\end{aligned}
$$

where $y_{i t, 1}^{b}$ is the deforestation in treated municipalities before the treatment, and $y_{i t, 0}^{b}$, the deforestation in non-treated municipalities before treatment. Note that the values for both groups do not need to be equal, because of parameter $\gamma$.

After the treatment, we have

$$
\begin{array}{lc}
y_{i t, 1}^{a}= & \alpha+\gamma+\delta+x_{i t}^{\prime} \beta+u_{i t} \\
y_{i t, 0}^{a}= & \alpha+x_{i t}^{\prime} \beta+u_{i t} .
\end{array}
$$

The control group represents the counter factual trajectory, the one treated municipalities would follow were they not subject to the intervention. Since the trajectories were not identical to begin with, we need to correct for this difference, and then we have our treatment effect:

$$
\mathrm{ATT}=E\left[y_{i t, 1}^{a}\right]-E\left[y_{i t, 1}^{b}\right]-\left[E\left[y_{i t, 0}^{a}\right]-E\left[y_{i t, 0}^{b}\right]\right]=\delta
$$

The estimated equation is

$$
y_{i t}=\alpha+\gamma \text { trat }_{i}+\delta \text { trat }_{i t}+\phi_{1} t+\phi_{2} u f_{i}+x_{i t}^{\prime} \beta+u_{i t},
$$


where $y_{i t}$ is a deforestation measure, trat $_{i}$ is a dummy variable indicating if municipality $i$ ever had a listed neighbour, trat $t_{i t}$ is a dummy variable indicating if municipality $i$ had listed neighbours in year $t, t$ and $u f_{i}$ capture time and state fixed effects, respectively, and $x_{i t}^{\prime}$ is a set of controls including agricultural characteristics, other policies implemented and economic structure of municipalities. We also include state and year fixed effects.

We use the ratio between the cleared area in a given year and the remaining forest area in the previous year as dependent variable. The remaining forest area was calculated from INPE data as the difference between total municipality area and the sum of accumulated deforestation, non-forest and water covered area. We chose not to use INPE's forest area due to the large number of null observations. ${ }^{1}$

The use of a relative measure of deforestation is necessary to ensure comparability amongst groups. Since the criteria to enter the list depend exclusively on absolute values of deforestation, listed municipalities are amongst the largest in the region. When using data on municipality level, we must take into account the considerable variance presented by municipalities' areas, as shown in figure 4b. As robustness checks, we also considered the cleared to observed forest area ratio, the cleared to total municipality area ratio and the absolute deforestation increment as dependent variables. Compared to these options, the share of remaining forest cleared has the advantage of compensating for previous deforestation, therefore taking into account the fact that as forest area gets smaller, clearing it becomes harder.

Figure 4 shows the trajectories for all three measures of deforestation. It indicates that both absolute and relative deforestation present similar trends for all groups, with the same turning points for the whole analysed period (2005-2012), in spite of different slopes. Therefore, this condition for identification of the difference-in-differences estimator is satisfied.

The neighbourhood criterion used to separate treatment and control groups is

\footnotetext{
${ }^{1}$ When forest area is under cloud on a given year's satellite image, INPE's forest area is equal to zero, even when forest area doesn't change between the previous and the next year. For our estimates, we corrected that.
} 
inverse distance. Because of large variance in the size of municipalities in the Amazon region, adjacency and nearest neighbours criteria are not adequate. The maximum distance cutoff is chosen according to the Akaike Information Criterion (AIC).

Following Bertrand, Duflo e Mullainathan (2002), we use cluster-robust standard errors to control for shocks that affect municipalities in the same micro-region. ${ }^{2}$ Still, even though we control for regional shocks, there's evidence in the literature that deforestation

\footnotetext{
${ }^{2}$ We also tested municipality-level clusters, i.e., robust standard errors, with no changes on variables' significance.
}

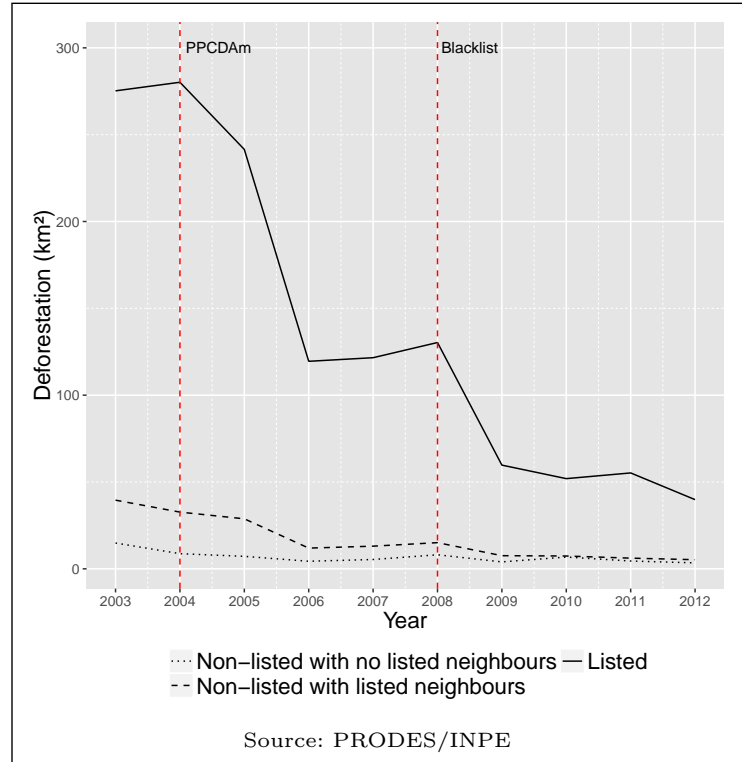

(a) Mean deforested area by group

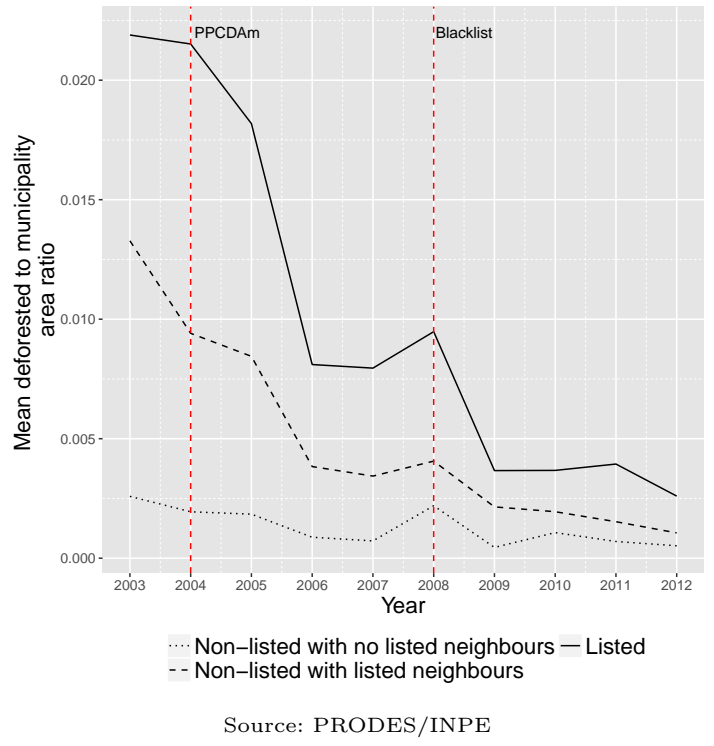

(c) Share of municipality area cleared

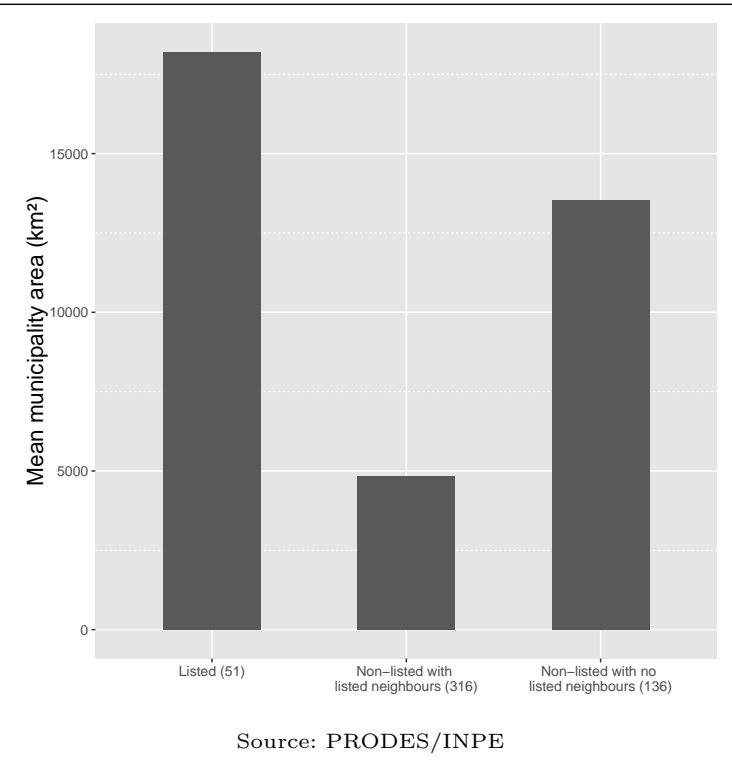

(b) Mean municipality area by group

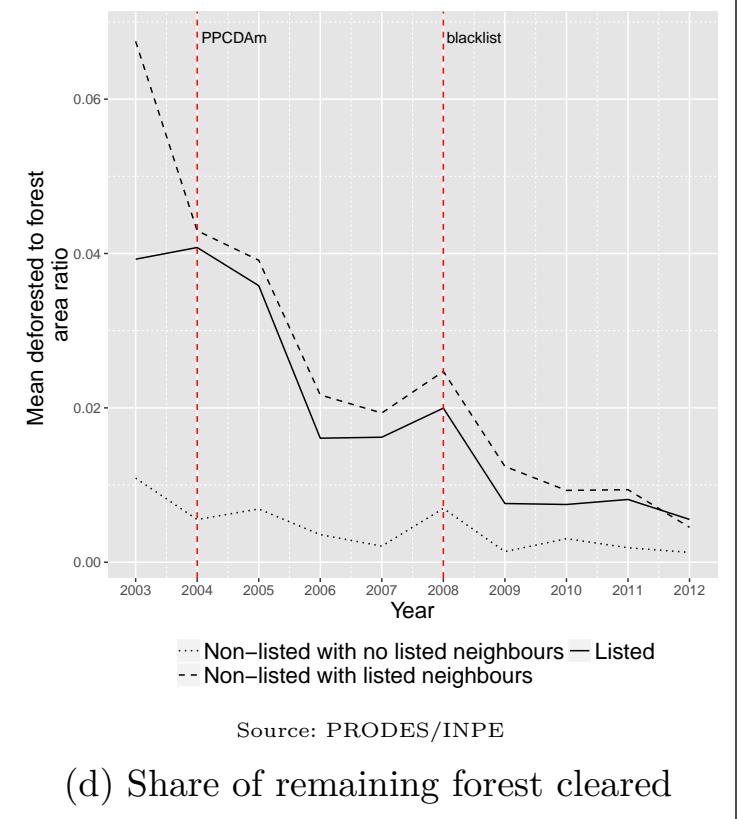

Figure 4 - Deforestation and area by group 
is a spatially correlated process. For this reason, we also test an alternative specification, using spatial econometrics methods.

\subsection{Spatial econometrics ${ }^{3}$}

Our usual ordinary least squares estimates assume that variables are randomly distributed with regard to location. However, there are situations where the values observed in one location depend on the values of neighbouring observations. In the presence of spatial dependence, non-spatial estimators may be inefficient, when only the error terms are spatially correlated, or even biased, if the dependent variable is spatially autocorrelated.

Spatial econometric methods deal with this problem by modelling spatial dependence and taking it into account during estimations. There are three main spatial models. The first, and simplest, describes exogenous interaction effects, when the dependent variable in one unit depends on the independent variables of neighbouring units. The Spatial Lag of X Model (SLX) is described in equation 4.7. This is the case, for example, when the treatment of one municipality affects its neighbours as well.

$$
Y=X \beta+W X \theta+\epsilon
$$

The second model, called Spatially Autoregressive Model (SAR), accounts for endogenous interaction effects, when the dependent variable depends on the neighbouring dependent variables. This situation typically arises when decisions are made simultaneously, and only the spatially dependent equilibrium is observed. The SAR model can be described as

$$
Y=\rho W Y+X \beta+\epsilon
$$

Finally, correlated effects, when the error terms are spatially correlated, are described by the Spatial Error Model (SEM) in equation 4.9, and are consistent with

\footnotetext{
${ }^{3}$ This section follows LeSage e Pace (2010) and Elhorst (2014).
} 
situations where unobserved variables follow a spatial pattern.

$$
Y=X \beta+u, u=\lambda W u+\epsilon
$$

where $Y$ is a vector of dependent variables, $X$ is a matrix of covariates, $u$ is the error term and $W$ is a matrix describing the neighbourhood relations among units.

These three models can be combined to build new models, up to a general spatial model that encompasses all three types of dependence. We, however, are only interested in two of them,

4

the Spatial Durbin Model (SDM), that combines SAR and SLX models, and the Spatial Durbin Error Model (SDEM), that combines SLX and SEM models:

$$
\begin{array}{cc}
\text { SDM: } & Y=\rho W Y+X \beta+W X \theta+\epsilon \\
\text { SDEM: } & Y=X \beta+W X \theta+u, u=\lambda W u+\epsilon
\end{array}
$$

The choice among spatial models is made in two steps: ${ }^{5}$ first, we conduct a Langrange Multiplier test on the non-spatial specification. This test estimates the SEM and the SAR version of the original non-spatial regression model and test for statistical significance of the spatial coefficients. The LM test allows us to determine if there is spatial correlation and to choose between an autoregressive and a spatial error model. Then, we estimate the chosen model with and without lags of the exogenous variables and verify their significance.

\subsection{Spatial difference-in-differences estimator ${ }^{6}$}

Let us now combine the difference-in-differences estimator described in section 4.1 and the spatial models described in section 4.2. For what follows, let $w_{i}$ be a $N \times 1$ vector

\footnotetext{
${ }^{4}$ The general spatial model, or General Nesting Spatial Model,

$$
Y=\rho W Y+X \beta+W X \theta+u, u=\lambda W u+\epsilon,
$$

suffers of identification issues and can only be computed in very specific cases, which is why it is not considered for our purposes. For further discussion, see Elhorst (2014), Chapter 2.

${ }^{5}$ See Florax, Folmer e Rey (2003) and Anselin e Florax (1995)

${ }^{6}$ This section follows Chagas, Azzoni e Almeida (2016)
} 
assigning weights to other municipalities, according to a neighbourhood criterion and $d_{t}$ an $N \times 1$ vector of treatment dummies $\left(d_{t_{j}}=1\right.$ if municipality $j$ was treated in year $t$ and $d_{t_{j}}=0$ otherwise).

If we suppose that deforestation follows a spatially dependent process, $\mu\left(x_{i t}\right)$, that can take any of the forms in section 4.2, our before-treatment equations in 4.2 become

$$
\begin{array}{r}
y_{i t, 1}^{b}=\alpha+\gamma+\mu\left(x_{i t}\right)+u_{i t} \\
y_{i t, 0}^{b}=\alpha+\mu\left(x_{i t}\right)+u_{i t}
\end{array}
$$

Once the treatment is implemented, assuming that it may affect the neighbours of the treated, we have

$$
\begin{array}{cc}
y_{i t, 1}^{a}= & \alpha+\gamma+\delta_{0}+w_{i}^{\prime} d_{t} \delta_{1}+\mu\left(x_{i t}\right)+u_{i t} \\
y_{i t, 0}^{a}= & w_{i}^{\prime} d_{i t} \delta_{1}+\mu\left(x_{i t}\right)+u_{i t}
\end{array}
$$

Notice that $\alpha$ captures the direct effect of blacklisting on the listed, while $\beta$ captures the indirect effects on both listed and non-listed neighbours of the listed. Therefore, three different effects of the policy can be identified:

$$
\begin{array}{rlrl}
\mathrm{ATE} & =E\left[y_{i t, 1}^{a}-y_{i t, 1}^{b}\right]-E\left[y_{i t, 0}^{a}-y_{i t, 0}^{b}\right] & =\delta_{0} \\
\mathrm{ATT} & = & E\left[y_{i t, 1}^{a}-y_{i t, 1}^{b}\right] & \\
\mathrm{ATNT}= & E\left[y_{i t, 0}^{a}-y_{i t, 0}^{b}\right] & & =\delta_{0}+w_{i}^{\prime} d_{i t} d_{i t} \delta_{1}
\end{array}
$$

In matrix notation, we have

$$
Y=\alpha \iota+\mu(X)+\left[\delta_{1}+\left(I_{T} \otimes W\right) \delta_{2}\right] D+U
$$

where $Y$ is a $N T \times 1$ vector, $\iota$ is a $N T \times 1$ vector of ones, $X$ is a $N T \times K$ matrix of covariates, $D$ is a $N T \times 1$ vector of dummy variables indicating the presence of treatment, $I_{T}$ is a square identity matrix of dimension $T \times T, \otimes$ is the Kroenecker product operator, $W$ is a $N \times N$ neighbourhood weight matrix and $U$ is a $N T \times 1$ vector of errors. $\mu, \alpha$ and $\beta$ are the parameters to be estimated.

The term $\left(I_{T} \otimes W\right) D \beta$ in equation 4.19 is the average indirect effect of treatment 
(on both treated and non-treated municipalities). However, this effect may vary among this two categories of municipalities, so that the average effect expressed by $\beta$ might be misleading. The different effects on treated and untreated neighbours could be captured through a decomposition of the $W$ matrix:

$$
I_{T} \otimes W=W_{t, t}+W_{t, n t}+W_{n t, t}+W_{n t, n t}
$$

where

$$
\begin{aligned}
W_{t, t} & =\operatorname{diag}(D) \times\left(I_{T} \otimes W\right) \times \operatorname{diag}(D) \\
W_{t, n t} & =\operatorname{diag}(D) \times\left(I_{T} \otimes W\right) \times \operatorname{diag}(\iota-D) \\
W_{n t, t} & =\operatorname{diag}(\iota-D) \times\left(I_{T} \otimes W\right) \times \operatorname{diag}(D) \\
W_{n t, n t} & =\operatorname{diag}(\iota-D) \times\left(I_{T} \otimes W\right) \times \operatorname{diag}(\iota-D)
\end{aligned}
$$

and $\operatorname{diag}(D)$ is a $N T \times N T$ matrix with $D$ in the main diagonal and zeros elsewhere, $\iota$ is a vector of ones and $W_{i, j}$ represents the neighbourhood relations of municipality $j$ on municipality $i(i, j=\mathrm{t}$, for treated, or nt, for untreated).

Then, substituting (4.20) in (4.19) gives us

$$
Y=\alpha \iota+\mu(X)+\left[\delta_{0}+W_{t, t} \delta_{1}+W_{n t, t} \delta_{2}\right] D+U^{7}
$$

Equation (4.25) is a Spatial Difference-in-Differences model that incorporates spillover effects of the treatment on non-treated municipalities. The $\mu(X)$ term's form depends on the spatial model chosen. Note that we cannot remove listed municipalities from the sample, because that would compromise the estimation of the correct spatial dependence process. However, we know that coefficients $\delta_{0}$ and $\delta_{1}$ area probably biased, so we're only interested in $\delta_{2}$, the ATNT estimator, that gives us the effects of blacklisting on non-listed neighbours of blacklisted municipalities.

\footnotetext{
${ }^{7}$ Note that $W_{n t, n t} D$ and $W_{t, n t} D$ are both null vectors, which is why they do not appear in the equation.
} 


\section{Data description}

Our database consists in a panel covering the municipalities within the Amazon biome from 2005 to 2012. The PPCDAm was launch in March 2004, so 2005 is the first year for which it was active for the whole INPE period. Since the criteria to enter the List were not published for 2013, we suspect other measures might not have been implemented, so we end our time series in 2012.

\subsection{Municipalities}

During the analysed period, the Brazilian Legal Amazon covered 771 municipalities in 9 different states. The data on municipalities, including maps, lists of new municipalities created in this period and of municipalities within the Amazon biome are provided by the Brazilian Institute of Geography and Statistics (IBGE), having as reference the municipality frontiers of 2007. Figure 5 shows the political division and the different biomes present in the Amazon region. Our final sample comprises the 503 municipalities that have more than $40 \%$ of their area within the Amazon biome.

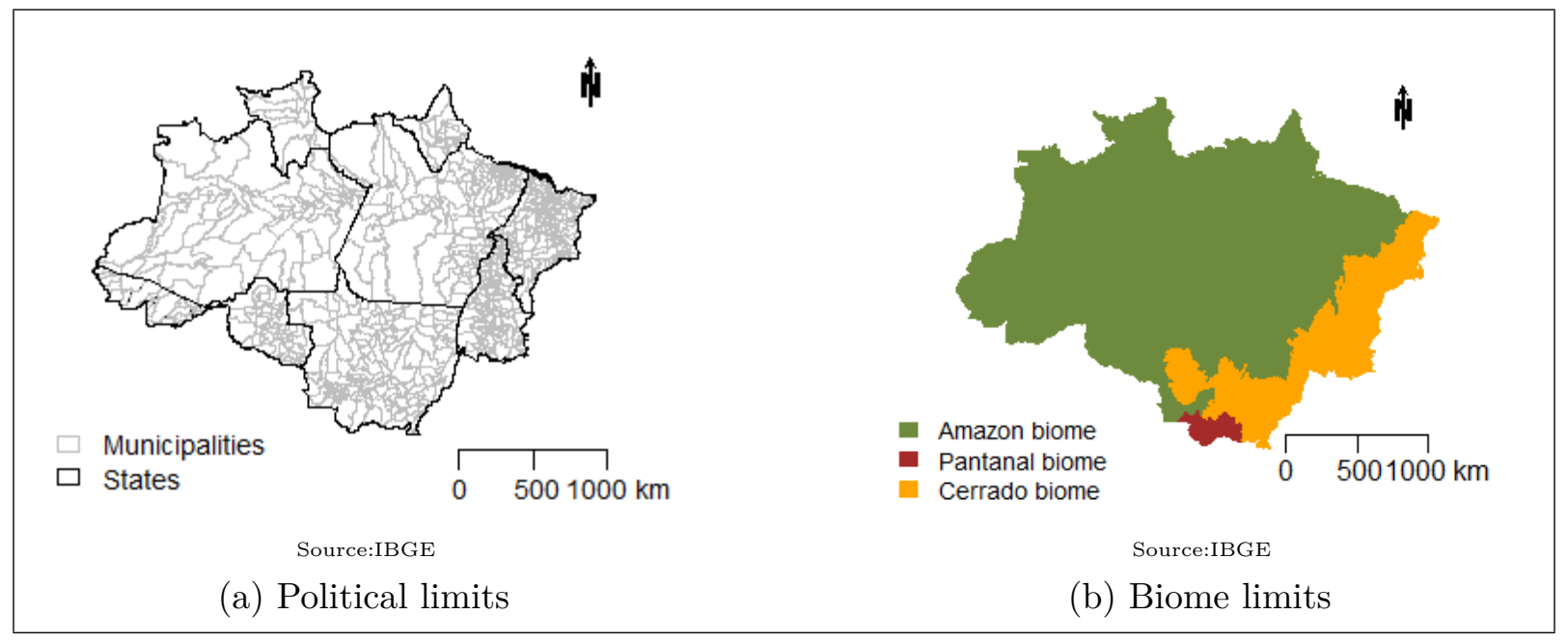

Figure 5 - Amazon region political and biome limits 


\subsection{Deforestation}

The National Institute for Spatial Research (INPE) has been measuring deforestation in Brazil via satellite since 1988, as part of the PRODES project. Since deforestation occurs during the dry season, most images are taken between July and September, and yearly deforestation rates are calculated having August 1st as reference-date. ${ }^{1}$ The land-use is identified from the satellite image with better visibility (minimum cloud coverage) and classified as forest, non-forest, cleared, water and cloud according to the image-fraction of soil, shadow and vegetation.

PRODES can identify cleared areas larger then 6,25 ha. Even though the main methodological procedures were maintained in order to make the series comparable, corrections for deforestation in areas under clouds have only been adopted starting in 2004 . The increment in deforestation is calculated by comparing the cleared area in the best image for each scene in one year to the one selected the previous year. The increment/total area ratio is then used to project deforested area under cloud coverage. Finally, the yearly deforestation rate is estimated through temporal compensation of the increments to a single reference-date.

PRODES also calculates total accumulated deforestation, which could be an important control, since municipalities with little remaining forest areas should present smaller deforestation rates. Other variables from this same database are the area unobserved and the area covered by cloud in final satellite images. As discussed by Butler e Moser (2007), these are relevant as measurement errors controls.

\subsection{Credit}

The value of rural credit provided to each municipality in a given year is available in the Statistical Yearbook of Rural Credit of the Brazilian Central Bank (BACEN) for the 2000-2012 period. Pfaff (1999) argues that credit supply is endogenous, once deforestation

\footnotetext{
${ }^{1}$ Since PRODES defines year $t$ as going from August $t-1$ to July $t$, we use this period to define the year for control variables whenever it is possible.
} 
attracts new bank agencies and increases the demand for credit. As a solution, we use the value of credit in the previous year in estimations, which is also consistent with the dynamics of deforestation. Since BACEN only makes public annualized data, information on credit could not be transformed into the PRODES yearly period. We used the IPCA index to express values in 1999 reais.

\subsection{Environmental fines}

Data on environmental fines were made available by IBAMA upon request. The database has information on all fines issued by IBAMA from 2000 to 2014, including name of the violator, type of infraction, process status and fine value.

\subsection{Protection areas and indigenous reserves}

Georeferenced data containing type of reserve, responsible authority and year of creation are provided by MMA. Since we only know the year when units were created, through the issuance of the law that created it, we consider the conservation unit active in the year that follows its creation, that is, we consider the creation of a conservation unit in any given year to affect deforestation starting in the next year. Georeferenced data on indigenous land, including date of creation, area and ethnicity, are available on the National Indian Foundation (FUNAI) website.

\subsection{Bolsa verde}

Since September 2011, families living in extreme poverty in areas considered important for environmental conservation receive a cash transfer from the federal government of $\mathrm{R} \$ 300$ every quarter. In order to receive the benefit, the family must be beneficiary of the Bolsa Família program and preferentially develop sustainable activities in conservation units or Environmentally Differentiated Settlements. The program is designed as a form of payment for environmental services and the families receive the benefit for at least 
two years. We tested two controls for this policy: number of families in the municipality receiving bolsa verde and value of the benefits received in constant 1999 prices. $^{2}$

\subsection{Economic structure}

We use data on PIB per capita, share of agriculture in municipalities' PIB, share of cultivated area and population density as additional controls in order to compare municipalities that present similar economic structures, since that may affect how they react to the listing. Municipalities that are heavily dependent in agricultural activities, for example, should suffer higher growth losses if they cannot expand their agricultural area. Population and PIB data come from IBGE's regional account system. PIB values were deflated to 1999 prices using the implicit government expenditure deflator. Cultivated area comes from IBGE's survey on municipalities's agricultural production (PAM), and include both temporary and permanent cultures.

\footnotetext{
${ }^{2}$ We used IPCA, a national consumer prices index, to deflate prices.
} 


\section{Results}

Results from regression model 4.1 are shown in table 1 . They indicate that, on average, having a listed neighbour reduces the share of remaining forest cleared in 0.57 percentage points every year. Pre-treatment deforestation mean was $2.52 \%$, so this represents a $23 \%$ reduction in deforestation. This negative effect is present across all specifications, although there's a reduction in the coefficient as more controls are added.

This result is consistent with literature evidence concerning spillover effects of environmental monitoring. It contradicts, however, to results found in Cisneros, Zhou e Börner (2015), that indicate there are no spillovers. Since non-listed municipalities are not the focus of this study, their identification suffers from some shortcomings we try to overcome. First of all, they use absolute deforestation as dependent variable, which (i) causes confusion with the criteria to enter the list and (ii) confuses identification, since this variables has different trajectories among groups. Second, their analysis include municipalities from other biomes, where measuring the area cleared is a challenge.

As previously discussed, our results may be biased because of spatial dependence. Following Florax, Folmer e Rey (2003) and Anselin e Florax (1995), we perform Lagrange Multiplier test with a queen neighbourhood criterion to test for the presence and the format of spatial auto-correlation. The LM test results', shown in table 2, indicate that a Spatial Error Model is preferred to an auto-regressive one. Results for the Spatial Lag of $\mathrm{X}$ version of that model, shown in table 3, point in the same direction. The choice between SEM and SDEM models is made based on the statistical significance of covariates' lags. In order to correct the inefficiencies in our estimates due to spatial dependence, we use a spatial difference-in-differences estimator, described in section 4.3.

To estimate the spatial regression, we need a fully balanced panel, so economic controls had to be excluded due to missing observations. Results are presented in table 4 . The first column of this table shows the coefficients from our main specification, excluding listed municipalities from the sample, is the same as column 4 in table 1 . In column 2, we present the coefficients from a non-spatial model including listed municipalities. The SEM 
Table 1 - Results from main specification

\begin{tabular}{|c|c|c|c|c|c|}
\hline & \multicolumn{5}{|c|}{ Dependent variable: } \\
\hline & \multicolumn{5}{|c|}{ Deforestation to remaining forest ratio } \\
\hline & $(1)$ & $(2)$ & (3) & $(4)$ & $(5)$ \\
\hline Non-listed with listed neighbours & $\begin{array}{c}-1.458^{* * *} \\
(0.253)\end{array}$ & $\begin{array}{c}-0.694^{* *} \\
(0.313)\end{array}$ & $\begin{array}{c}-0.620^{* *} \\
(0.316)\end{array}$ & $\begin{array}{c}-0.570^{*} \\
(0.319)\end{array}$ & $\begin{array}{c}-0.549^{*} \\
(0.333)\end{array}$ \\
\hline Accumulated deforestation $_{t-1}$ & & & $\begin{array}{c}0.037^{* * *} \\
(0.013)\end{array}$ & $\begin{array}{l}0.033^{* *} \\
(0.016)\end{array}$ & $\begin{array}{l}0.033^{* *} \\
(0.016)\end{array}$ \\
\hline Squared accumulated deforestation $_{t-1}$ & & & $\begin{array}{l}-0.0001 \\
(0.0002)\end{array}$ & $\begin{array}{l}-0.0001 \\
(0.0002)\end{array}$ & $\begin{array}{l}-0.0001 \\
(0.0002)\end{array}$ \\
\hline Cultivated area & & & $\begin{array}{c}0.006 \\
(0.009)\end{array}$ & $\begin{array}{c}0.005 \\
(0.009)\end{array}$ & $\begin{array}{c}0.002 \\
(0.009)\end{array}$ \\
\hline Protected areas & & & & $\begin{array}{l}-0.004 \\
(0.006)\end{array}$ & $\begin{array}{l}-0.003 \\
(0.006)\end{array}$ \\
\hline Indigenous land & & & & $\begin{array}{l}-0.002 \\
(0.003)\end{array}$ & $\begin{array}{l}-0.001 \\
(0.004)\end{array}$ \\
\hline Bolsa verde & & & & $\begin{array}{l}0.048^{* *} \\
(0.020)\end{array}$ & $\begin{array}{c}0.054^{* * *} \\
(0.021)\end{array}$ \\
\hline Green Municipalities Program & & & & $\begin{array}{l}-0.502 \\
(0.333)\end{array}$ & $\begin{array}{l}-0.494 \\
(0.333)\end{array}$ \\
\hline 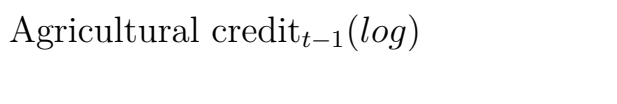 & & & & & $\begin{array}{c}0.051 \\
(0.055)\end{array}$ \\
\hline PIB per capita $t_{-1}(\log )$ & & & & & $\begin{array}{l}-0.102 \\
(0.164)\end{array}$ \\
\hline Agricultural share of $\mathrm{PIB}_{t-1}$ & & & & & $\begin{array}{c}0.512 \\
(0.355)\end{array}$ \\
\hline Population density $_{t-1}$ & & & & & $\begin{array}{c}-0.00002 \\
(0.0005)\end{array}$ \\
\hline State and year fixed effects & No & Yes & Yes & Yes & Yes \\
\hline Observations & 3,491 & 3,491 & 3,302 & 3,302 & 3,038 \\
\hline Adjusted $\mathrm{R}^{2}$ & 0.053 & 0.151 & 0.202 & 0.204 & 0.200 \\
\hline
\end{tabular}

Notes: All specifications include measurement error controls and group intercepts. Monetary values are in 1999 BRL. Standard errors are clustered by micro region. ${ }^{*} \mathrm{p}<0.1 ;{ }^{* *} \mathrm{p}<0.05 ;{ }^{* * *} \mathrm{p}<0.01$. 
Table 2 - LM test for spatial specification

\begin{tabular}{cccc}
\hline \hline Model & Statistic & DF & P-value \\
\hline SEM & 901.32 & 1 & 0.0000 \\
SAR & 648.33 & 1 & 0.0000 \\
SEM (robust) & 258.02 & 1 & 0.0000 \\
SAR (robust) & 5.0277 & 1 & 0.0249 \\
\hline \hline
\end{tabular}

Table 3 - LM test for spatial specification in SLX model

\begin{tabular}{cccc}
\hline \hline Model & Statistic & DF & P-value \\
\hline SDEM & 904.01 & 1 & 0.0000 \\
SDM & 827.88 & 1 & 0.0000 \\
SDEM (robust) & 80.328 & 1 & 0.0000 \\
SDM (robust) & 4.2004 & 1 & 0.0404 \\
\hline \hline
\end{tabular}

model then includes lagged errors; the SLX, lagged values for the independent variables; and the SDEM, lags of errors and independents variables.

The significance of neighbours' covariates indicates the best model to describe spatial dependence follows an SDEM specification. This means (i) that independent variables from other municipalities affect the land clearing decision and (ii) that we have spatially correlated unobserved variables affecting deforestation.

To determine the most appropriate neighbourhood matrix, we estimate the SDEM model with different neighbourhood criteria and choose the one with the highest AIC value. Results from these estimations are shown in table 5 and indicate that the queen matrix is the most appropriate to our analysis. This was the matrix used for estimations presented in both tables 1 and $4^{1}$

\footnotetext{
${ }^{1}$ Group composition under the different matrices tested is shown in Appendix V.
} 
Table 4 - Results from Spatial model

\begin{tabular}{|c|c|c|c|c|c|}
\hline & \multicolumn{5}{|c|}{ Dependent variable: } \\
\hline & \multicolumn{5}{|c|}{ Deforestation to remaining forest ratio } \\
\hline & (Main) & (Non-spatial) & $(\mathrm{SEM})$ & $(\mathrm{SLX})$ & $(\mathrm{SDEM})$ \\
\hline Non-listed with listed neighbours & $\begin{array}{c}-0.570^{* * *} \\
(0.198)\end{array}$ & $\begin{array}{c}-0.542^{* * *} \\
(0.182)\end{array}$ & $\begin{array}{c}-0.498^{* *} \\
(0.202)\end{array}$ & $\begin{array}{c}-0.532^{\text {*** }} \\
(0.182)\end{array}$ & $\begin{array}{c}-0.487^{* *} \\
(0.202)\end{array}$ \\
\hline Listed & & $\begin{array}{c}-0.381 \\
(0.275)\end{array}$ & $\begin{array}{c}-0.393 \\
(0.319)\end{array}$ & $\begin{array}{c}-0.366 \\
(0.276)\end{array}$ & $\begin{array}{c}-0.379 \\
(0.320)\end{array}$ \\
\hline Accumulated deforestation ${ }_{t-1}$ & $\begin{array}{c}0.033^{* * *} \\
(0.007)\end{array}$ & $\begin{array}{c}0.038^{* * *} \\
(0.007)\end{array}$ & $\begin{array}{c}0.032^{* * *} \\
(0.007)\end{array}$ & $\begin{array}{c}0.035^{* * *} \\
(0.014)\end{array}$ & $\begin{array}{c}0.033^{* * *} \\
(0.007)\end{array}$ \\
\hline Squared accumulated deforestation $_{t-1}$ & $\begin{array}{l}-0.000 \\
(0.000)\end{array}$ & $\begin{array}{c}-0.000^{*} \\
(0.000)\end{array}$ & $\begin{array}{l}-0.000 \\
(0.000)\end{array}$ & $\begin{array}{c}-0.000^{*} \\
(0.000)\end{array}$ & $\begin{array}{l}-0.000 \\
(0.000)\end{array}$ \\
\hline Cultivated area & $\begin{array}{c}0.005 \\
(0.009)\end{array}$ & $\begin{array}{c}0.002 \\
(0.008)\end{array}$ & $\begin{array}{l}-0.003 \\
(0.008)\end{array}$ & $\begin{array}{l}-0.003 \\
(0.010)\end{array}$ & $\begin{array}{l}-0.004 \\
(0.009)\end{array}$ \\
\hline Protected area & $\begin{array}{c}-0.004^{* *} \\
(0.002)\end{array}$ & $\begin{array}{c}-0.003^{*} \\
(0.002)\end{array}$ & $\begin{array}{c}-0.004^{* *} \\
(0.002)\end{array}$ & $\begin{array}{l}-0.004 \\
(0.002)\end{array}$ & $\begin{array}{c}-0.004^{* *} \\
(0.002)\end{array}$ \\
\hline Indigenous reserves & $\begin{array}{l}-0.002 \\
(0.004)\end{array}$ & $\begin{array}{l}-0.002 \\
(0.004)\end{array}$ & $\begin{array}{c}-0.005 \\
(0.004)\end{array}$ & $\begin{array}{c}-0.005 \\
(0.004)\end{array}$ & $\begin{array}{l}-0.005 \\
(0.004)\end{array}$ \\
\hline Bolsa verde (log) & $\begin{array}{c}0.048 \\
(0.032)\end{array}$ & $\begin{array}{c}0.041 \\
(0.030)\end{array}$ & $\begin{array}{c}0.005 \\
(0.031)\end{array}$ & $\begin{array}{c}0.023 \\
(0.032)\end{array}$ & $\begin{array}{c}0.006 \\
(0.031)\end{array}$ \\
\hline Green Municipalities Program & $\begin{array}{c}-0.502^{* *} \\
(0.241)\end{array}$ & $\begin{array}{c}-0.504^{* *} \\
(0.212)\end{array}$ & $\begin{array}{l}-0.357 \\
(0.238)\end{array}$ & $\begin{array}{l}-0.256 \\
(0.279)\end{array}$ & $\begin{array}{l}-0.362 \\
(0.238)\end{array}$ \\
\hline Neighbours' accumulated deforestation ${ }_{t-1}$ & & & & $\begin{array}{c}0.001 \\
(0.001)\end{array}$ & $\begin{array}{c}0.000 \\
(0.001)\end{array}$ \\
\hline Neighbours' cultivated area & & & & $\begin{array}{c}0.002 \\
(0.003)\end{array}$ & $\begin{array}{c}0.002 \\
(0.003)\end{array}$ \\
\hline Neighbours' protected area & & & & $\begin{array}{c}0.000 \\
(0.001)\end{array}$ & $\begin{array}{c}0.001 \\
(0.001)\end{array}$ \\
\hline Neighbours' indigenous reserves & & & & $\begin{array}{c}-0.002 \\
(0.001)\end{array}$ & $\begin{array}{c}-0.003^{*} \\
(0.002)\end{array}$ \\
\hline Neighbours is in GMP & & & & $\begin{array}{c}-0.082 \\
(0.058)\end{array}$ & $\begin{array}{c}-0.066 \\
(0.076)\end{array}$ \\
\hline Neighbours' bolsa verde (log) & & & & $\begin{array}{l}0.011^{* *} \\
(0.005)\end{array}$ & $\begin{array}{l}0.010^{* *} \\
(0.006)\end{array}$ \\
\hline$\overline{\mathrm{R}^{2}}$ & 0.211 & 0.222 & & 0.224 & \\
\hline Adj. $\mathrm{R}^{2}$ & 0.204 & 0.216 & & 0.216 & \\
\hline Num. obs. & 3,302 & 3,584 & 3,584 & 3,584 & 3,584 \\
\hline $\mathrm{AIC}$ & & & $-16,724.663$ & & $-16,729.124$ \\
\hline Log Likelihood & & & $7,958.661$ & & $7,955.490$ \\
\hline Lambda: statistic & & & 0.102 & & 0.102 \\
\hline Lambda: p-value & & & 0.000 & & 0.000 \\
\hline
\end{tabular}

Notes: All specifications include measurement error controls, group intercepts and state and year fixed effects. Monetary values are in 1999 BRL. Standard errors in non-spatial specifications are clustered by micro region. ${ }^{*} \mathrm{p}<0.1$; ${ }^{* *} \mathrm{p}<0.05 ;{ }^{* * *} \mathrm{p}<0.01$. 


\begin{tabular}{|c|c|c|c|c|c|c|}
\hline \multicolumn{7}{|c|}{ Dependent variable: } \\
\hline \multicolumn{7}{|c|}{ Deforestation to remaining forest ratio } \\
\hline & (Queen) & $(2.1)$ & $(2.2)$ & $(2.3)$ & $(2.4)$ & $(2.5)$ \\
\hline Treated & $-0.4866^{* *}$ & $-0.3519^{* *}$ & $-0.2719^{*}$ & -0.2227 & -0.0928 & -0.0530 \\
\hline 0.1414 & -0.0136 & 0.0234 & -0.0910 & -0.1748 & & \\
\hline & $(0.2022)$ & $(0.1540)$ & $(0.1545)$ & $(0.1546)$ & $(0.1543)$ & $(0.1543)$ \\
\hline$(0.1554)$ & $(0.1590)$ & $(0.1594)$ & $(0.1626)$ & $(0.1649)$ & & \\
\hline Obs & 3,584 & 3,584 & 3,584 & 3,584 & 3,584 & 3,584 \\
\hline 3,584 & 3,584 & 3,584 & 3,584 & 3,584 & & \\
\hline AIC & $-16,729.12$ & $-16,659.23$ & $-16,658.77$ & $-16,654.48$ & $-16,660.33$ & $-16,658.93$ \\
\hline$-16,665.50$ & $-16,662.08$ & $-16,663.78$ & $-16,654.12$ & $-16,649.70$ & & \\
\hline Log Likelihood & $7,955.49$ & $8,135.33$ & $8,144.03$ & $8,139.96$ & $8,144.13$ & $8,147.70$ \\
\hline $8,150.84$ & $8,151.22$ & $8,152.48$ & $8,142.16$ & $8,136.53$ & & \\
\hline Lambda: statistic & 0.1024 & 0.0137 & 0.0130 & 0.0125 & 0.0120 & 0.0115 \\
\hline 0.0111 & 0.0107 & 0.0104 & 0.0102 & 0.0099 & & \\
\hline Lambda: p-value & 0.0000 & 0.0000 & 0.0000 & 0.0000 & 0.0000 & 0.0000 \\
\hline 0.0000 & 0.0000 & 0.0000 & 0.0000 & 0.0000 & & \\
\hline
\end{tabular}

Notes: All specifications include measurement error controls, group intercepts and state and year fixed effects. Monetary values are in 1999 BRL. ${ }^{*} \mathrm{p}<0.1 ;{ }^{* *} \mathrm{p}<0.05 ;{ }^{* * *} \mathrm{p}<0.01$. 
We observe negative and significant coefficients for having listed neighbours for the first three neighbourhood matrices. The inclusion of listed municipalities in the sample reduces the coefficient for having a listed neighbours, as does that of spatially dependent errors. Our benchmark spatial model indicates a reduction of 0.49 percentage points in the share of remaining forest cleared. This represents a $19 \%$ reduction in deforestation.

Coefficient estimates for other independent variables are consistent with our non-spatial specification, except for the significance of the Green Municipalities Program dummy. This is explained by the different standard errors used in the non-spatial and the spatial models. For our non-spatial specification, we clustered standard errors by micro-region, while the spatial model considers a spatially dependent error structure as described in equation $4.11 .^{2}$

With few exceptions, results seem to reveal a monotonic reduction on the estimates of the List's effect on non-listed neighbours as the cut-off distance increases. This might indicate that the further a municipality is from the listed ones, the smaller the impact of the listing. Such a result is consistent with our model indicating that there's a spillover in police presence to municipalities close to the listed.

\footnotetext{
${ }^{2}$ The spatial modelling of the error should be preferred to cluster-robust standard errors, since the latter is only efficiency for block-diagonal spatial processes Anselin e Arribas-Bel (2013).
} 


\section{Robustness checks}

To check our results, we conducted some robustness exercises. First, we test other measures of deforestation as dependent variables. We used absolute deforestation and deforestation as share of municipality area in both spatial and non-spatial specifications. Our estimates, presented in table 6, show that negative and significant effects are robust to changes in the definition of deforestation. Second, we estimate placebo regression pushing treatment year back one, two, and three years. Results are in table 8 and coefficients for having listed neighbours are non-significant in all three tests.

We then test different definitions of neighbourhood. The benchmark queen contiguity matrix is compared, in table ??, to inverse distance matrices with different cut-offs. As happens in the spatial specification, having listed neighbours has a negative and significant coefficient for the first neighbourhood criteria, as that coefficient is reduced and becomes non-significant when the cut-off distance increases.

Finally, we designed a test to shed some light on the mechanisms behind the observed effects. We use matching techniques to create control and treatment groups with equal chances of being listed so we can test our proposed mechanism against the alternative represented by the possible threat of economic slowdown if a municipality should join the list. Once we match municipalities on the probability of being listed, we're comparing groups facing the same risk of suffering such slowdown, so differences in the policy's observed effect should be attributed to other causes. 
Table 6 - Results with different dependent variables

\begin{tabular}{|c|c|c|c|c|}
\hline & $(1)$ & $(2)$ & $(3)$ & $(4)$ \\
\hline Non-listed with listed neighbours & $\begin{array}{c}-12.047^{* * *} \\
(2.954)\end{array}$ & $\begin{array}{c}-0.230^{* * *} \\
(0.067)\end{array}$ & $\begin{array}{c}-8.448^{* *} \\
(3.777)\end{array}$ & $\begin{array}{c}-0.139^{* * *} \\
(0.037)\end{array}$ \\
\hline Listed & & & $\begin{array}{c}-40.004^{* * *} \\
(5.985)\end{array}$ & $\begin{array}{c}-0.330^{* * *} \\
(0.058)\end{array}$ \\
\hline Accumulated deforestation $_{t-1}$ & $\begin{array}{c}0.027 \\
(0.113)\end{array}$ & $\begin{array}{c}0.015^{* * *} \\
(0.003)\end{array}$ & $\begin{array}{l}-0.043 \\
(0.128)\end{array}$ & $\begin{array}{c}0.017^{* * *} \\
(0.001)\end{array}$ \\
\hline Squared accumulated deforestation ${ }_{t-1}$ & $\begin{array}{c}-0.002^{*} \\
(0.001)\end{array}$ & $\begin{array}{c}-0.0002^{* * *} \\
(0.00002)\end{array}$ & $\begin{array}{l}-0.001 \\
(0.001)\end{array}$ & $\begin{array}{c}-0.000^{* * *} \\
(0.000)\end{array}$ \\
\hline Cultivated area & $\begin{array}{l}-0.107 \\
(0.075)\end{array}$ & $\begin{array}{c}0.001 \\
(0.002)\end{array}$ & $\begin{array}{c}0.006 \\
(0.159)\end{array}$ & $\begin{array}{c}-0.003^{*} \\
(0.002)\end{array}$ \\
\hline Protected areas & $\begin{array}{l}-0.029 \\
(0.035)\end{array}$ & $\begin{array}{c}-0.001^{* *} \\
(0.001)\end{array}$ & $\begin{array}{l}-0.043 \\
(0.037)\end{array}$ & $\begin{array}{c}-0.001^{* * *} \\
(0.000)\end{array}$ \\
\hline Indigenous land & $\begin{array}{l}-0.013 \\
(0.045)\end{array}$ & $\begin{array}{l}-0.001 \\
(0.001)\end{array}$ & $\begin{array}{c}-0.135^{* *} \\
(0.065)\end{array}$ & $\begin{array}{c}-0.001^{* *} \\
(0.001)\end{array}$ \\
\hline Bolsa verde $(\log )$ & $\begin{array}{l}-0.157 \\
(0.154)\end{array}$ & $\begin{array}{c}-0.0003 \\
(0.003)\end{array}$ & $\begin{array}{c}0.042 \\
(0.579)\end{array}$ & $\begin{array}{l}-0.006 \\
(0.006)\end{array}$ \\
\hline Green Municipalities Program & $\begin{array}{c}1.479 \\
(1.981)\end{array}$ & $\begin{array}{l}-0.027 \\
(0.053)\end{array}$ & $\begin{array}{c}1.266 \\
(4.429)\end{array}$ & $\begin{array}{l}-0.026 \\
(0.043)\end{array}$ \\
\hline Neighbours' accumulated deforestation ${ }_{t-1}$ & & & $\begin{array}{c}-0.030^{* *} \\
(0.013)\end{array}$ & $\begin{array}{l}-0.000 \\
(0.000)\end{array}$ \\
\hline Neighbours' cultivated area & & & $\begin{array}{c}-0.107^{*} \\
(0.064)\end{array}$ & $\begin{array}{l}0.001^{*} \\
(0.001)\end{array}$ \\
\hline Neighbours' protected area & & & $\begin{array}{c}0.002 \\
(0.012)\end{array}$ & $\begin{array}{l}0.000^{*} \\
(0.000)\end{array}$ \\
\hline Neighbours' indigenous reserves & & & $\begin{array}{c}0.145^{* * *} \\
(0.029)\end{array}$ & $\begin{array}{c}0.000 \\
(0.000)\end{array}$ \\
\hline Neighbours in GMP & & & $\begin{array}{l}2.961^{* *} \\
(1.463)\end{array}$ & $\begin{array}{l}-0.008 \\
(0.015)\end{array}$ \\
\hline Neighbours' bolsa verde (log) & & & $\begin{array}{c}-0.720^{* * *} \\
(0.113)\end{array}$ & $\begin{array}{c}0.001 \\
(0.001)\end{array}$ \\
\hline State and year fixed effects & Yes & Yes & Yes & Yes \\
\hline Observations & 3,302 & 3,302 & 3,584 & 3,584 \\
\hline Adjusted $\mathrm{R}^{2}$ & 0.319 & 0.279 & & \\
\hline $\mathrm{AIC}$ & & & $37,476.44$ & $4,538.17$ \\
\hline Log Likelihood & & & $18,421.85$ & $1,750.8$ \\
\hline Lambda: statistic & & & 0.106 & 0.113 \\
\hline Lambda: p-value & & & 0.000 & 0.000 \\
\hline
\end{tabular}

Notes: All specifications include measurement error controls, group intercepts and state and year fixed effects. Monetary values are in 1999 BRL. Standard errors are clustered by micro region. ${ }^{*} \mathrm{p}<0.1 ;{ }^{* *} \mathrm{p}<0.05$; ${ }^{* * *} \mathrm{p}<0.01$. 
Table 7 - Results from placebo regressions

\begin{tabular}{lccc}
\hline \hline & \multicolumn{3}{c}{ Dependent variable: } \\
\cline { 2 - 4 } & Deforestation to remaining forest ratio \\
& $(1)$ & $(2)$ & $(3)$ \\
\hline Non-listed with listed neighbours & -0.255 & -0.427 & 0.482 \\
& $(0.538)$ & $(0.536)$ & $(0.568)$ \\
Accumulated deforestation ${ }_{t-1}$ & $0.055^{* * *}$ & $0.056^{* * *}$ & $0.055^{* * *}$ \\
& $(0.018)$ & $(0.018)$ & $(0.019)$ \\
Squared accumulated deforestation & & & \\
& 0.00002 & 0.00001 & 0.00002 \\
Cultivated area & $(0.0002)$ & $(0.0002)$ & $(0.0002)$ \\
& & & 0.037 \\
Protected areas & 0.039 & 0.037 & $(0.027)$ \\
& $(0.027)$ & $(0.027)$ & -0.007 \\
Indigenous land & & & $(0.006)$ \\
Adjusted $\mathrm{R}^{2}$ & -0.008 & -0.007 & -0.004 \\
\hline \hline
\end{tabular}

Notes: All specifications include measurement error controls and group intercepts. Monetary values are in 1999 BRL. Standard errors are clustered by micro region. Green Municipalities Program and Bolsa Verde values were excluded from this specification because there was no variation in the matched sample. ${ }^{*} \mathrm{p}<0.1 ;{ }^{* *} \mathrm{p}<0.05 ;{ }^{* * *} \mathrm{p}<0.01$. 
Table 8 - Results with different spatial matrices

\begin{tabular}{|c|c|c|c|c|c|c|}
\hline & \multicolumn{3}{|c|}{ Dependent variable: } & & & \multirow[b]{3}{*}{$(3)$} \\
\hline & \multicolumn{5}{|c|}{ Deforestation to remaining forest ratio } & \\
\hline & (Queen) & $(2.1)$ & $(2.3)$ & $(2.5)$ & $(2.7)$ & \\
\hline Non-listed with listed neighbours & $\begin{array}{c}-0.570^{*} \\
(0.319)\end{array}$ & $\begin{array}{c}-0.543^{* * *} \\
(0.159)\end{array}$ & $\begin{array}{c}-0.531^{* * *} \\
(0.192)\end{array}$ & $\begin{array}{c}-0.412 \\
(0.267)\end{array}$ & $\begin{array}{c}-0.373 \\
(0.334)\end{array}$ & $\begin{array}{c}-0.535 \\
(0.327)\end{array}$ \\
\hline Accumulated deforestation & $\begin{array}{l}0.033^{* *} \\
(0.016)\end{array}$ & $\begin{array}{l}0.032^{* *} \\
(0.016)\end{array}$ & $\begin{array}{l}0.033^{* *} \\
(0.016)\end{array}$ & $\begin{array}{l}0.033^{* *} \\
(0.016)\end{array}$ & $\begin{array}{c}0.034^{* *} \\
(0.016)\end{array}$ & $\begin{array}{l}0.034^{* *} \\
(0.016)\end{array}$ \\
\hline Squared accumulated deforestation & $\begin{array}{c}-0.0001 \\
(0.0002)\end{array}$ & $\begin{array}{c}-0.0001 \\
(0.0002)\end{array}$ & $\begin{array}{l}-0.0001 \\
(0.0002)\end{array}$ & $\begin{array}{r}-0.0001 \\
(0.0002)\end{array}$ & $\begin{array}{l}-0.0001 \\
(0.0002)\end{array}$ & $\begin{array}{c}-0.0001 \\
(0.0002)\end{array}$ \\
\hline Cultivated area & $\begin{array}{c}0.005 \\
(0.009)\end{array}$ & $\begin{array}{c}0.007 \\
(0.009)\end{array}$ & $\begin{array}{c}0.007 \\
(0.009)\end{array}$ & $\begin{array}{c}0.006 \\
(0.009)\end{array}$ & $\begin{array}{c}0.006 \\
(0.009)\end{array}$ & $\begin{array}{c}0.006 \\
(0.009)\end{array}$ \\
\hline Protected areas & $\begin{array}{l}-0.004 \\
(0.006)\end{array}$ & $\begin{array}{l}-0.005 \\
(0.006)\end{array}$ & $\begin{array}{l}-0.006 \\
(0.006)\end{array}$ & $\begin{array}{l}-0.005 \\
(0.006)\end{array}$ & $\begin{array}{c}-0.005 \\
(0.006)\end{array}$ & $\begin{array}{l}-0.005 \\
(0.006)\end{array}$ \\
\hline Indigenous land & $\begin{array}{l}-0.002 \\
(0.003)\end{array}$ & $\begin{array}{l}-0.002 \\
(0.003)\end{array}$ & $\begin{array}{l}-0.002 \\
(0.003)\end{array}$ & $\begin{array}{l}-0.002 \\
(0.003)\end{array}$ & $\begin{array}{l}-0.002 \\
(0.003)\end{array}$ & $\begin{array}{l}-0.002 \\
(0.003)\end{array}$ \\
\hline Bolsa verde (log) & $\begin{array}{l}0.048^{* *} \\
(0.020)\end{array}$ & $\begin{array}{l}0.045^{* *} \\
(0.021)\end{array}$ & $\begin{array}{l}0.048^{* *} \\
(0.021)\end{array}$ & $\begin{array}{l}0.048^{* *} \\
(0.021)\end{array}$ & $\begin{array}{l}0.049^{* *} \\
(0.020)\end{array}$ & $\begin{array}{l}0.050^{* *} \\
(0.020)\end{array}$ \\
\hline Green Municipalities Program & $\begin{array}{l}-0.502 \\
(0.333)\end{array}$ & $\begin{array}{c}-0.523^{*} \\
(0.317)\end{array}$ & $\begin{array}{c}-0.548^{*} \\
(0.314)\end{array}$ & $\begin{array}{c}-0.549^{*} \\
(0.318)\end{array}$ & $\begin{array}{c}-0.547^{*} \\
(0.316)\end{array}$ & $\begin{array}{c}-0.554^{*} \\
(0.317)\end{array}$ \\
\hline Mean number of neighbours & 5.37 & 37.05 & 41.63 & 46.36 & 51.18 & 58.48 \\
\hline Max number of neighbours & 14 & 110 & 122 & 132 & 146 & 162 \\
\hline Observations & 3,302 & 3,302 & 3,302 & 3,302 & 3,302 & 3,302 \\
\hline Adjusted $\mathrm{R}^{2}$ & 0.204 & 0.205 & 0.205 & 0.204 & 0.203 & 0.205 \\
\hline
\end{tabular}

Notes: All specifications include measurement error controls and group intercepts. All specification include state and year fixed effects. Monetary values are in 1999 BRL. Standard errors are clustered by micro region. ${ }^{*} \mathrm{p}<0.1 ;{ }^{* *} \mathrm{p}<0.05 ;{ }^{* * *} \mathrm{p}<0.01$.

In order to guarantee common support in the probability of being treated between non-listed municipalities with listed neighbours and nonlisted municipalities with no listed neighbours, we had to trim observations in the first group with a propensity score equal to or smaller than $56 \%{ }^{1}$. This trimming has the additional advantage of removing from the sample municipalities that might have been intentionally kept out of the List, despite

\footnotetext{
${ }^{1}$ This is the largest propensity score observed in municipalities with no listed neighbours.
} 
presenting high values for the criteria, which further reduces the possibility of analysing endogenously created groups.

We matched groups on propensity score by year. A t-test for difference in means in table 9 shows that groups are balanced regarding the propensity score variable. Results with matched sample are shown in table 10 and are consistent with those from our main specification.

Estimates for the effect of the blacklist in non-listed neighbours of listed municipalities indicate a $21 \%$ reduction in yearly deforestation for the benchmark model in column 4 . With this subsample, economic controls become significant in column 5 , and the coefficient for having listed neighbours increases, indicating an average reduction of $25 \%$ in yearly deforestation. Therefore, even if we do not take into account the possible economic threat represented by the List, we still have a negative and significant spillover on non-listed neighbours.

Table 9 - Matching balance test

\begin{tabular}{lcc}
\hline \hline & Before Matching & After Matching \\
\hline Mean treatment & 0.0180 & 0.0180 \\
Mean control & 0.0037 & 0.0156 \\
Std mean diff & $24.08^{* * *}$ & 4.0277 \\
\hline \hline
\end{tabular}

Note: ${ }^{*} \mathrm{p}<0.1 ;{ }^{* *} \mathrm{p}<0.05 ;{ }^{* * *} \mathrm{p}<0.01$ 
Table 10 - Results with matched sample

\begin{tabular}{|c|c|c|c|c|c|}
\hline & \multicolumn{5}{|c|}{ Dependent variable: } \\
\hline & \multicolumn{5}{|c|}{ Deforestation to remaining forest ratio } \\
\hline & $(1)$ & $(2)$ & $(3)$ & $(4)$ & $(5)$ \\
\hline Non-listed with listed neighbours & $\begin{array}{c}-1.477^{* * *} \\
(0.115)\end{array}$ & $\begin{array}{c}-0.665^{* * *} \\
(0.157)\end{array}$ & $\begin{array}{c}-0.587^{* * *} \\
(0.153)\end{array}$ & $\begin{array}{c}-0.536^{* * *} \\
(0.153)\end{array}$ & $\begin{array}{c}-0.621^{* * *} \\
(0.156)\end{array}$ \\
\hline Accumulated deforestation & $\begin{array}{c}1.228^{* * *} \\
(0.165)\end{array}$ & $\begin{array}{c}0.934^{* * *} \\
(0.179)\end{array}$ & $\begin{array}{c}0.933^{* * *} \\
(0.161)\end{array}$ & $\begin{array}{c}0.865^{* * *} \\
(0.155)\end{array}$ & $\begin{array}{c}0.940^{* * *} \\
(0.169)\end{array}$ \\
\hline Squared accumulated deforestation & & & $\begin{array}{c}0.039^{* * *} \\
(0.005)\end{array}$ & $\begin{array}{c}0.034^{* * *} \\
(0.006)\end{array}$ & $\begin{array}{c}0.037^{* * *} \\
(0.007)\end{array}$ \\
\hline Cultivated area & & & $\begin{array}{l}-0.0001 \\
(0.0001)\end{array}$ & $\begin{array}{l}-0.0001 \\
(0.0001)\end{array}$ & $\begin{array}{l}-0.0001 \\
(0.0001)\end{array}$ \\
\hline Protected areas & & & $\begin{array}{l}-0.001 \\
(0.004)\end{array}$ & $\begin{array}{c}-0.0005 \\
(0.004)\end{array}$ & $\begin{array}{l}-0.005 \\
(0.003)\end{array}$ \\
\hline Indigenous land & & & & $\begin{array}{c}-0.005^{* *} \\
(0.002)\end{array}$ & $\begin{array}{l}-0.003 \\
(0.002)\end{array}$ \\
\hline Bolsa verde $(\log )$ & & & & $\begin{array}{l}-0.002 \\
(0.002)\end{array}$ & $\begin{array}{c}0.002 \\
(0.002)\end{array}$ \\
\hline Green Municipalities Program & & & & $\begin{array}{c}0.078^{* * *} \\
(0.009)\end{array}$ & $\begin{array}{c}0.082^{* * *} \\
(0.010)\end{array}$ \\
\hline Agricultural credit $_{t-1}(\log )$ & & & & & $\begin{array}{l}0.0004 \\
(0.028)\end{array}$ \\
\hline PIB per capita $t_{t-1}(\log )$ & & & & & $\begin{array}{l}-0.123 \\
(0.080)\end{array}$ \\
\hline Agricultural share of $\mathrm{PIB}_{t-1}$ & & & & & $\begin{array}{c}1.186^{* * *} \\
(0.244)\end{array}$ \\
\hline Population density $_{t-1}$ & & & & & $\begin{array}{c}-0.0003^{*} \\
(0.0002)\end{array}$ \\
\hline State and year fixed effects & No & Yes & Yes & Yes & Yes \\
\hline Observations & 3,481 & 3,481 & 3,292 & 3,292 & 3,028 \\
\hline Adjusted $\mathrm{R}^{2}$ & 0.068 & 0.193 & 0.264 & 0.265 & 0.263 \\
\hline
\end{tabular}

Notes: All specifications include measurement error controls and group intercepts. Monetary values are in 1999 BRL. Standard errors are clustered by micro region. ${ }^{*} \mathrm{p}<0.1 ;{ }^{* *} \mathrm{p}<0.05 ;{ }^{* * *} \mathrm{p}<0.01$. 


\section{Final remarks}

This study investigated the spillover effects of a blacklisting policy, the Priority Municipalities List. Unlike other evaluations of this policy, we are mainly interested in the effects it had on non-listed neighbours of listed municipalities. We also contribute to the literature by considering a spatial estimator, which to our knowledge had never been adopted to evaluate deforestation policy impacts. Our results suggest that the Priority Municipalities List affect municipalities that are not listed, reducing the share of remaining forest cleared yearly by $19 \%$ to $23 \%$, on average.

As modeled in section 3, the List's effect on non-listed municipalities could, a priori, be either positive or negative. The negative coefficients observed in our estimates indicate that the incentive to reduce deforestation caused by increased probability of being punished is greater than the incentives to expand agricultural activities into neighbouring municipalities.

Our first estimates consist on a difference-in-differences regression with a sample of municipalities in the Amazon biome that were not part of the blacklist. Municipalities in our treatment group are the neighbours of listed, while those in our control group shared no borders with any municipality in the list. Results indicate that the list caused a $23 \%$ reduction in deforestation on non-listed neighbours of listed municipalities. Once we correct for spatial dependence, using a spatial difference-in-differences estimator that account both for lagged effect of explanatory variables and for spatial correlation of error terms, the estimated effect falls to a $19 \%$ reduction. The negative and 
significant coefficient is robust to changes in the definition of deforestation, and placebo regressions present non-significant coefficients for the treatment variable.

When we vary the neighbourhood matrix, allowing for different neighbourhood criteria, we get significant reductions in deforestation for the queen contiguity matrix and for the two inverse distance matrices with the smallest cut-offs. As the cut-off distance increases, considering municipalities further away from the listed as treated, the effect decreases and becomes non-significant. This finding is consistent with our proposed mechanism, that suggests the reduction in deforestation comes from an increase in environmental authorities' presence in the neighbourhood of listed municipalities.

Though we do not perform a definitive causal test indicating that the observed impact is due to stricter police presence, results from a subsample with balanced propensity scores allow us to dismiss the possibility of economic threats as an alternative mechanism. Since unlike blacklisted municipalities, non-listed neighbours are not subject to further restrictions, the stricter enforcement remains the most plausible mechanism at work.

Our findings diverge from those presented by Cisneros, Zhou e Börner (2015), who find no significant effect on neighbours of blacklisted municipalities. Their strategy is very similar to ours, excluding listed municipalities from the sample and considering an adjacency neighbourhood criterion. The different results may be due to (i) their inclusion of municipalities ouside the Amazon biome, where measuring the area cleared is a challenge; and (ii) their choice of dependent variable. Where they use an absolute measure of deforestation, 
that may lead to confusion with the listing criteria and to identification issues due to group comparability, our outcome variable is the share of remaining forest cleared. However, our robustness checks include a test of absolute deforestation as dependent variable, and a negative and significant coefficient is still found.

These results are in line with those presented by Assunção, Gandour e Rocha (2012), Assunção, Gandour e Rocha (2013) and Assunção e Rocha (2014), highlighting the importance of command and control instruments to reduce deforestation. They also indicate that previous works probably underestimated the policy's effect in the Amazon biome as whole, and suggests that the spatial distribution of environmental law enforcement can be used to improve efficiency of deforestation policies. 



\section{Bibliography}

ALIX-GARCIA, J. M.; SHAPIRO, E. N.; SIMS, K. R. E. Forest conservation and slippage: Evidence from mexico's national payments for ecosystem services program. Land Economics, v. 88, n. 4, 2012. Disponível em: < http: //EconPapers.repec.org/RePEc:uwp:landec:v:88:y:2012:iv:1:p:613-638>. 21

AMBIENTE, M. Ministério do M. Brazilian policy to tackle deforestation in the amazon. In: Rio+20 United Nations Conference on Sustainable Development. [S.l.: s.n.], 2012. 23

ANSELIN, L.; ARRIBAS-BEL, D. Spatial fixed effects and spatial dependence in a single cross-section. Papers in Regional Science, Wiley Online Library, v. 92, n. 1, p. 3-17, 2013. 52

ANSELIN, L.; FLORAX, R. J. Small sample properties of tests for spatial dependence in regression models: Some further results. In: New directions in spatial econometrics. [S.1.]: Springer, 1995. p. 21-74. 40, 47

ARIMA, E. Y. et al. Public policies can reduce tropical deforestation: Lessons and challenges from brazil. Land Use Policy, Elsevier, v. 41, p. 465-473, 2014. 19,23

ASSUNÇÃO, J.; GANDOUR, C.; ROCHA, R. Deforestation slowdown in the Legal Amazon: prices or policies? [S.1.], 2012. 19, 23, 24, 61

ASSUNÇÃO, J.; GANDOUR, C.; ROCHA, R. DETERing deforestation in the Brazilian Amazon: environmental monitoring and law enforcement. [S.1.], 2013. 19, 25, 27, 33, 61

ASSUNÇÃO, J.; ROCHA, R. Getting greener by going black: The priority municipalities in brazil. Rio de Janeiro, Brazil: Climate Policy Initiative, 2014. 19, 23, 25, 29, 61

BECKER, G. S. Crime and punishment: An economic approach, 76 j. pol. econ. 169 (1968). Becker16976J. Pol. Econ, 1968. 20

BERTRAND, M.; DUFLO, E.; MULLAINATHAN, S. How much should we trust differences-in-differences estimates? [S.1.], 2002. 38

BUTLER, J.; MOSER, C. Cloud cover and satellite images of deforestation. Land economics, University of Wisconsin Press, v. 83, n. 2, p. 166-173, 2007. 44 
CHAGAS, A. L.; AZZONI, C. R.; ALMEIDA, A. N. A spatial difference-indifferences analysis of the impact of sugarcane production on respiratory diseases. Regional Science and Urban Economics, v. 59, p. 24 - 36, 2016. 40

CHOMITZ, K. M.; THOMAS, T. S. Determinants of land use in amazonia: a fine-scale spatial analysis. American Journal of Agricultural Economics, Oxford University Press, v. 85, n. 4, p. 1016-1028, 2003. 21, 35

CISNEROS, E.; ZHOU, S. L.; BÖRNER, J. Naming and shaming for conservation: Evidence from the brazilian amazon. PloS one, Public Library of Science, v. 10, n. 9, p. e0136402, 2015. 19, 23, 26, 29, 47, 60

CIVIL, . C. Plano de Ação para a Prevenção e Controle do Desmatamento na Amazônia Legal. [S.l.]: Casa Civil da Presidência da República, 2004. 23

ELHORST, J. P. Spatial econometrics: from cross-sectional data to spatial panels. [S.1.]: Springer, 2014. 39, 40

FLORAX, R. J.; FOLMER, H.; REY, S. J. Specification searches in spatial econometrics: the relevance of hendry's methodology. Regional Science and Urban Economics, Elsevier, v. 33, n. 5, p. 557-579, 2003. 40, 47

GRAY, W. B.; SHIMSHACK, J. P. The effectiveness of environmental monitoring and enforcement: A review of the empirical evidence. Review of Environmental Economics and Policy, Oxford University Press, v. 5, n. 1, p. 3-24, 2011. 20

HARGRAVE, J.; KIS-KATOS, K. Economic causes of deforestation in the brazilian amazon: A panel data analysis for the 2000s. Environmental and Resource Economics, Springer, v. 54, n. 4, p. 471-494, 2013. 19, 21, 23, 27, 35

HERRERA, D. Spillover Conservation around Protected Areas in the Brazilian Amazon: Frontier Dynamics and Variation in Nearby Deforestation 'Blockage' (Reverse Leakage). Tese (Doutorado) — Duke University, 2015. 21

INFORMAçãO, M. Ministério da Ciência Tecnologia e. Estimativas anuais de emissões de gases de efeito estufa no Brasil. [S.1.], 2013. 23

INPE. Metodologia para o Calculo da Taxa Anual de Desmatamento na Amazônia Legal. [S.1.], 2013. 23

IPCC. Climate change 1995: Impacts, adaptations, and mitigation of climate change: Scientific-technical analyses. Cambridge University Press, 1996. 23 
LESAGE, J.; PACE, R. K. Introduction to spatial econometrics. [S.l.]: CRC press, 2010. 39

MAIA, H. et al. Avaliação do plano de ação para prevenção e controle do desmatamento na amazônia legal: Ppcdam: 2007-2010. Brasil. Instituto de Pesquisa Econômica Aplicada (Ipea), 2011. 19, 23, 24

PFAFF, A. What drives deforestation in the brazilian amazon?: evidence from satellite and socioeconomic data. Journal of Environmental Economics and Management, Elsevier, v. 37, n. 1, p. 26-43, 1999. 21, 31, 35, 44

PFAFF, A. et al. Protected areas' impacts on brazilian amazon deforestation: examining conservation-development interactions to inform planning. PloS one, Public Library of Science, v. 10, n. 7, p. e0129460, 2015. 21

POLINSKY, A. M.; SHAVELL, S. The economic theory of public enforcement of law. [S.1.], 1999. 20, 31

ROBALINO, J. A. Land conservation policies and income distribution: who bears the burden of our environmental efforts? Environment and Development Economics, Cambridge Univ Press, v. 12, n. 04, p. 521-533, 2007. 21

ROBAlinO, J. A.; PFAFF, A. Contagious development: Neighbor interactions in deforestation. Journal of Development Economics, Elsevier, v. 97, n. 2 , p. $427-436,2012.21,35$

RUSSELL, C. S. et al. Enforcing pollution control laws. [S.l.]: Routledge, 2013. 20

SHIMSHACK, J. P.; WARD, M. B. Regulator reputation, enforcement, and environmental compliance. Journal of Environmental Economics and Management, Elsevier, v. 50, n. 3, p. 519-540, 2005. 20

SOUSA, P. Q. Decreasing deforestation in the southern brazilian amazon - the role of administrative sanctions in mato grosso state. Forests, Multidisciplinary Digital Publishing Institute, v. 7, n. 3, p. 66, 2016. 24

SOUZA-RODRIGUES, E. Demand for deforestation in the amazon. Job Market Paper, 2011. 25, 33

STIGLER, G. J. The optimum enforcement of laws. In: Essays in the economics of crime and punishment. [S.1.]: UMI, 1974. p. 55-67. 20

YOUNG, C. E. F. Economic adjustment policies and the environment: a case study of Brazil. [S.l.]: University of London, 1997. 31 



\section{Appendix I}

\begin{tabular}{|c|c|c|c|}
\hline State & "Municipality & Year of Entrance & Year of Exit \\
\hline $\mathrm{AM}$ & Lábrea & 2008 & - \\
\hline MT & Alta Floresta & 2008 & 2012 \\
\hline MT & Aripuanã & 2008 & - \\
\hline MT & Brasnorte & 2008 & 2013 \\
\hline MT & Colniza & 2008 & - \\
\hline MT & Confresa & 2008 & - \\
\hline MT & Cotriguaçu & 2008 & - \\
\hline MT & Gaúcha do Norte & 2008 & - \\
\hline MT & Juína & 2008 & - \\
\hline MT & Marcelândia & 2008 & 2013 \\
\hline MT & Nova Bandeirantes & 2008 & - \\
\hline MT & Nova Maringá & 2008 & - \\
\hline MT & Nova Ubiratã & 2008 & - \\
\hline MT & Paranaíta & 2008 & - \\
\hline MT & Peixoto de Azevedo & 2008 & - \\
\hline MT & Porto dos Gaúchos & 2008 & - \\
\hline MT & Querência & 2008 & 2011 \\
\hline MT & São Félix do Araguaia & 2008 & - \\
\hline MT & Vila Rica & 2008 & - \\
\hline PA & Altamira & 2008 & - \\
\hline PA & Brasil Novo & 2008 & 2013 \\
\hline PA & Cumaru do Norte & 2008 & - \\
\hline PA & Dom Eliseu & 2008 & 2012 \\
\hline PA & Novo Progresso & 2008 & - \\
\hline PA & Novo Repartimento & 2008 & - \\
\hline PA & Paragominas & 2008 & 2010 \\
\hline PA & Rondon do Pará & 2008 & - \\
\hline PA & Santa Maria das Barreiras & 2008 & - \\
\hline PA & Santana do Araguaia & 2008 & 2012 \\
\hline PA & São Félix do Xingu & 2008 & - \\
\hline PA & Ulianópolis & 2008 & 2012 \\
\hline RO & Machadinho d'Oeste & 2008 & - \\
\hline RO & Nova Mamoré & 2008 & - \\
\hline RO & Pimenta Bueno & 2008 & - \\
\hline RO & Porto Velho & 2008 & - \\
\hline MA & Amarante do Maranhão & 2009 & - \\
\hline MT & Feliz Natal & 2009 & 2013 \\
\hline MT & Juara & 2009 & - \\
\hline PA & Itupiranga & 2009 & - \\
\hline PA & Marabá & 2009 & - \\
\hline PA & Pacajá & 2009 & - \\
\hline PA & Tailândia & 2009 & 2013 \\
\hline $\mathrm{RR}$ & Mucajaí & 2009 & - \\
\hline $\mathrm{AM}$ & Boca do Acre & 2011 & - \\
\hline MA & Grajaú & 2011 & - \\
\hline MT & Alto Boa & 2011 & - \\
\hline MT & Cláudia & 2011 & - \\
\hline MT & Santa Carmem & 2011 & - \\
\hline MT & Tapurah & 2011 & - \\
\hline PA & Moju & 2011 & - \\
\hline $\mathrm{PA}$ & Anapu & 2012 & - \\
\hline PA & Senador José Porfírio & 2012 & - \\
\hline
\end{tabular}

Source: MMA. 


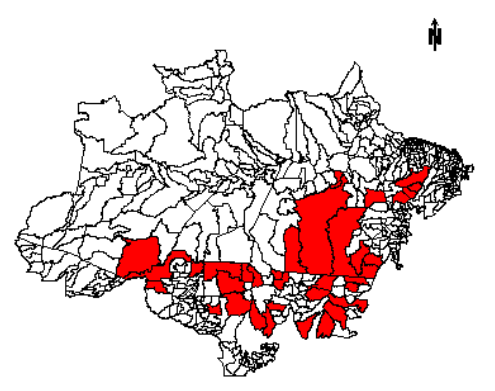

- Prority municipalities

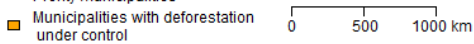

(a) Listed municipalities in 2008

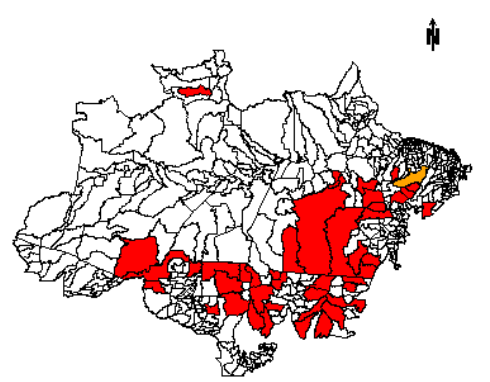

- Prority municipalities

Municipalitites with deforestation
under control

(c) Listed municipalities in 2010

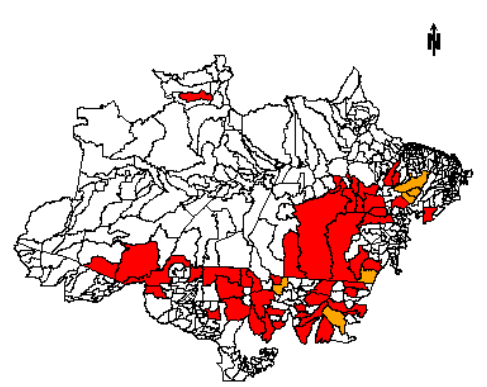

- Prority municipalities

口 Municipalities with deforestation

(e) Listed municipalities in 2012

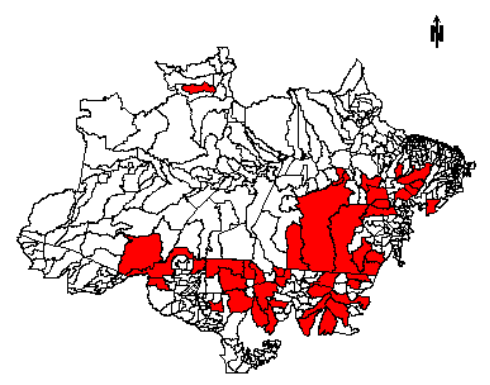

- Prority municipalities

Municipalities with deforestation
under control

(b) Listed municipalities in 2009

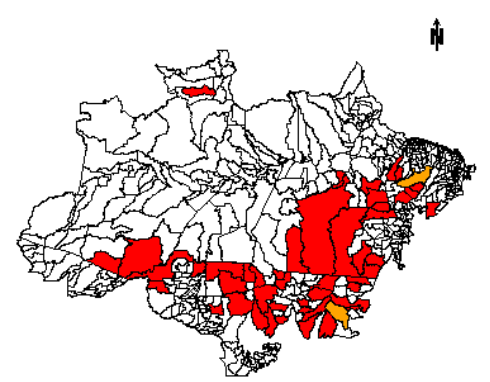

- Prority municipalities

Municipalities with deforestation
under control

(d) Listed municipalities in 2011

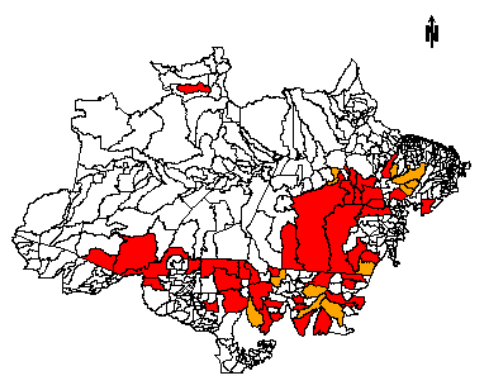

- Prority municipalities

- Municipalities with deforestation $\begin{gathered}1 \\ \text { under control }\end{gathered}$

(f) Listed municipalities in 2013

Figure 6 - Blacklisted municipalities 


\section{Appendix II}

\section{Announced criteria}

- 2008 (Portaria MMA \#28 of January 24th, 2008)

(i) total deforested area;

(ii) total deforested area in the last three years;

(iii) increase in deforestation rate in at last three of last five years.

- 2009 (Portaria MMA \#102 of March 24th, 2009)

(iv) cleared area in 2008 equal to or bigger then $200 \mathrm{~km}^{2}$;

(v) (a) increase in deforestation rate in at least 4 of the last five years and (b) accumulated deforestation in the last three equal to or bigger than $90 \mathrm{~km}^{2}$.

- 2010 (Portaria MMA \#66 of March 24th, 2010)

(iv) cleared area in 2009 equal to or bigger then $150 \mathrm{~km}^{2}$;

(v) (a) increase in deforestation rate in at least 4 of the last five years and (b) accumulated deforestation in the last three equal to or bigger than $90 \mathrm{~km}^{2}$.

- 2011 (Portaria MMA \#175 of May 24th, 2011)

(iv) (a) increase in deforestation rate from 2009 to 2010, (b) deforestation rate in 2010 equal to or bigger than $80 \mathrm{~km}^{2}$ or (c) deforestation 
identified by DETER between August 2010 and April 2011 close to or bigger than $40 \mathrm{~km}^{2}$.

- 2012 (Portaria MMA \#322 of September 28th, 2012)

(iv) increase in deforestation from 2010 to 2011 eleven and deforestation in 2011 equal to or bigger than $80 \mathrm{~km}^{2}$. 


\section{Propensity score analysis}

Table 11 - Propensity score results

\begin{tabular}{|c|c|c|c|c|}
\hline & \multicolumn{4}{|c|}{ Dependent variable: } \\
\hline & \multicolumn{4}{|c|}{ Probability of entering the list } \\
\hline & $(2008)$ & $(2009)$ & $(2011)$ & $(2012)$ \\
\hline Criterion 1 & $\begin{array}{c}0.0005^{* *} \\
(0.0002)\end{array}$ & $\begin{array}{c}0.0005 \\
(0.001)\end{array}$ & $\begin{array}{c}0.001^{*} \\
(0.001)\end{array}$ & $\begin{array}{l}0.001^{* * *} \\
(0.0002)\end{array}$ \\
\hline Criterion 2 & $\begin{array}{c}0.012^{* * *} \\
(0.002)\end{array}$ & & $\begin{array}{l}-0.058 \\
(0.038)\end{array}$ & $\begin{array}{c}-0.004 \\
(0.008)\end{array}$ \\
\hline Criterion 3 & $\begin{array}{c}-0.273 \\
(0.625)\end{array}$ & $\begin{array}{l}-3.526 \\
(7.897)\end{array}$ & $\begin{array}{c}-0.006 \\
(1.955)\end{array}$ & $\begin{array}{c}0.052 \\
(0.537)\end{array}$ \\
\hline Criterion 4 & & $\begin{array}{c}0.084 \\
(0.058)\end{array}$ & & \\
\hline Criterion $4 \mathrm{a}$ & & & $\begin{array}{c}-0.894 \\
(1.913)\end{array}$ & $\begin{array}{c}1.013^{*} \\
(0.578)\end{array}$ \\
\hline Criterion $4 \mathrm{~b}$ & & & $\begin{array}{c}0.179^{*} \\
(0.099)\end{array}$ & $\begin{array}{c}0.063^{* * *} \\
(0.023)\end{array}$ \\
\hline Criterion $4 \mathrm{c}$ & & & $\begin{array}{c}8.917^{* * *} \\
(2.434)\end{array}$ & \\
\hline Criterion $5 \mathrm{a}$ & & $\begin{array}{c}0.030 \\
(0.023)\end{array}$ & & \\
\hline Criterion 5b & & $\begin{array}{c}17.134 \\
(12.017)\end{array}$ & & \\
\hline Observations & 502 & 467 & 459 & 497 \\
\hline Log Likelihood & -48.525 & -4.810 & -9.752 & -68.310 \\
\hline Akaike Inf. Crit. & 105.050 & 21.620 & 33.504 & 148.620 \\
\hline
\end{tabular}

Note: ${ }^{*} \mathrm{p}<0.1 ;{ }^{* *} \mathrm{p}<0.05 ;{ }^{* *} \mathrm{p}<0.01$ 


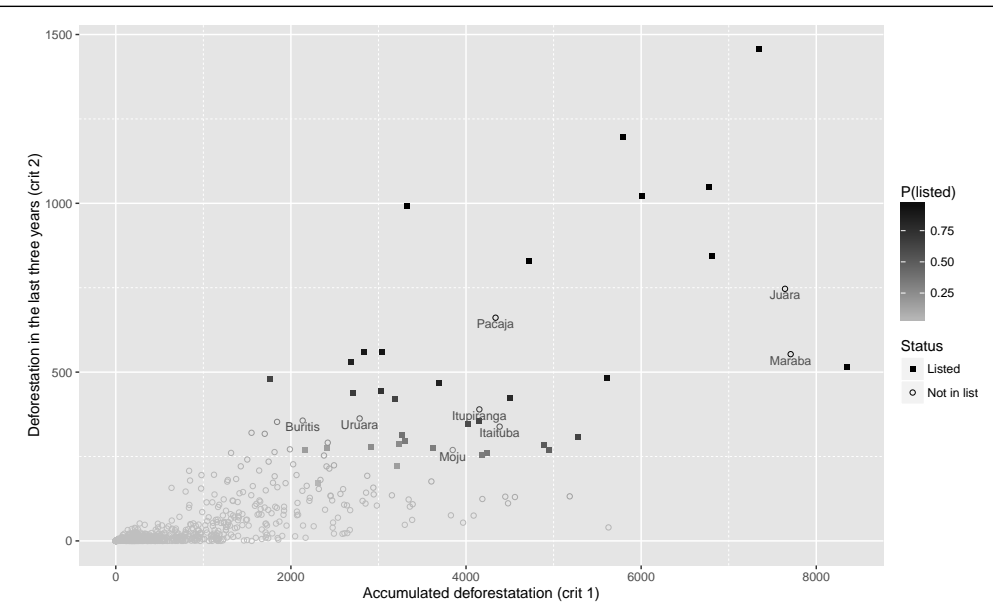

(a) Probability of being listed in 2008

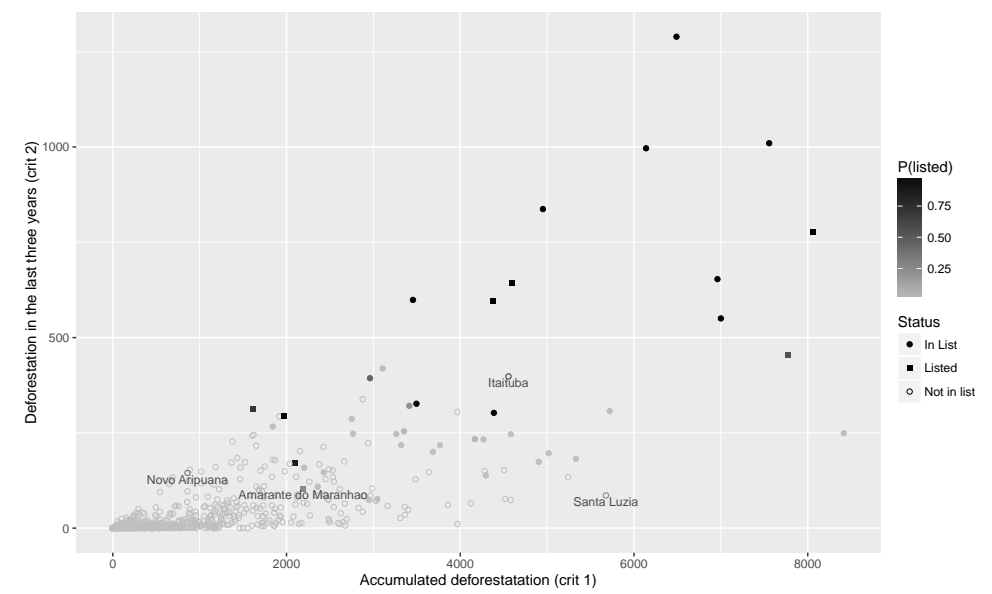

(b) Probability of being listed in 2009

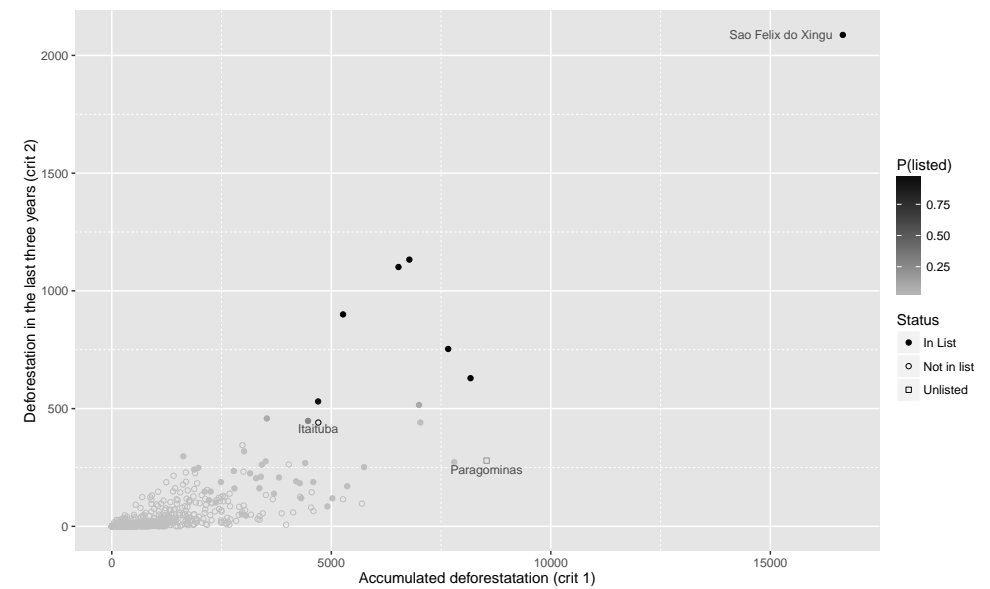

(c) Probability of being listed in 2010

Figure 7 - Propensity score and entrance to the Priority Municipality List from 2008 to 2010 


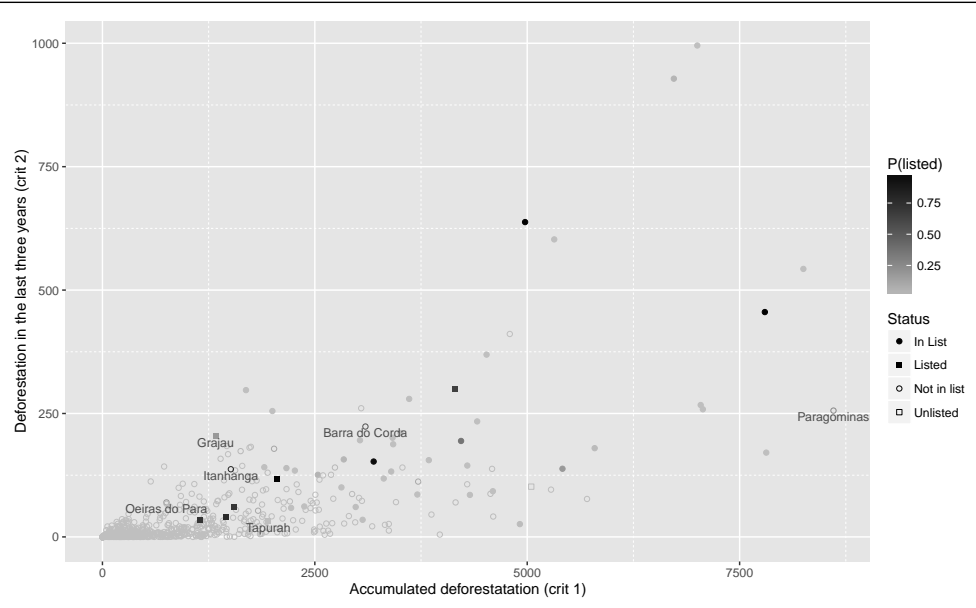

(a) Probability of being listed in 2011

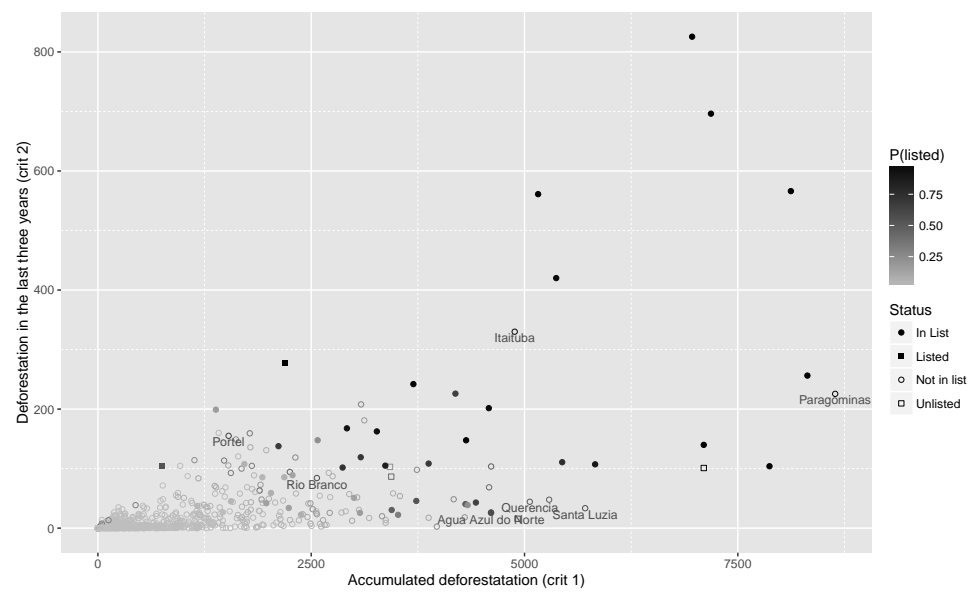

(b) Probability of being listed in 2012

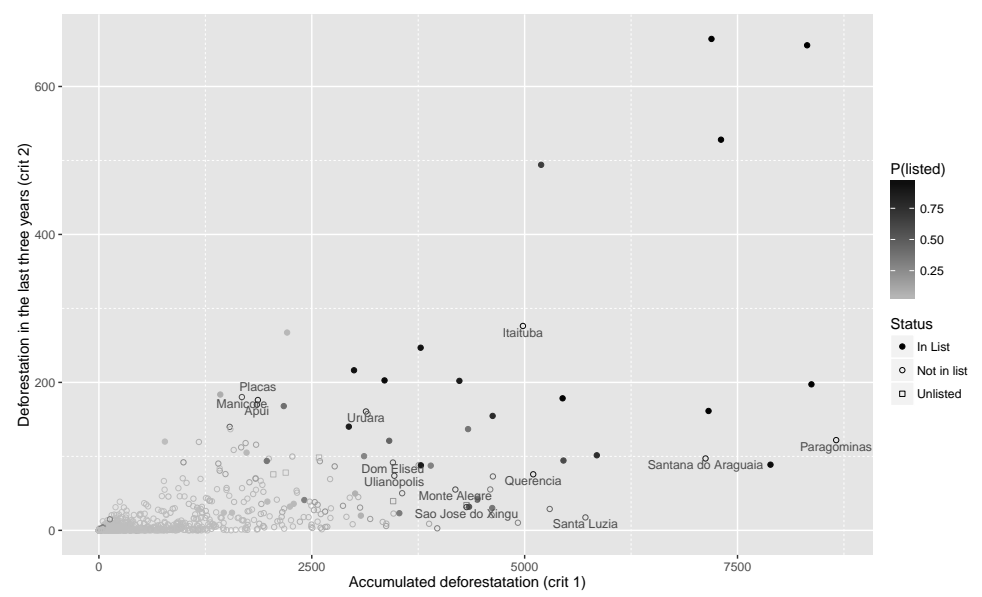

(c) Probability of being listed in 2013

Figure 8 - Propensity score and entrance to the Priority Municipality List from 2011 to 2013 



\section{Appendix III}

This section develops the theoretical model discussed and relaxes the assumptions made. We depart from condition (3.4), which states that a producer $i$ in municipality $j$ will only move to municipality $k$ if

$$
\left(1-p_{i k t}^{e}\right) V_{k j t}^{c}-p_{i k t}^{e} L_{k j t}-\phi\left(d_{k, j}\right)>\left(1-p_{i j t}^{e}\right) V_{i j t}^{c}-p_{i j t}^{e} L_{i j t}
$$

Rearranging the terms in (3.4), we have

$$
\underbrace{\left(1-p_{i k t}^{e}\right) V_{k j t}^{c}-p_{i k t}^{e} L_{k j t}}_{V_{i k t}^{d}}-[\underbrace{\left[\left(1-p_{i j t}^{e}\right) V_{i j t}^{c}-p_{i j t}^{e} L_{i j t}\right.}_{V_{i j t}^{d}}]>\phi\left(d_{k, j}\right) .
$$

Therefore, the agent will only move if the difference in the expected income is greater then the relocation costs.

Now, the agent will decide to clear the land in municipality $j$ if (i) it yields her a positive income, i.e., $V_{i j t}^{d}>0$; and (ii) the income from producing in municipality $j$ is equal to or greater than that of moving and producing in another municipality, that is, $V_{i j t}^{d} \geq V_{i k t}^{d} \phi\left(d_{k, j}\right), \forall k$, which gives us the following condition:

$$
d_{i j t}=1\left[V_{i j t}^{d}>0\right] \times 1\left[V_{i k t}^{d}-V_{i j t}^{d} \leq \phi\left(d_{k, j}\right)\right]
$$

On the other hand, the agent will move to municipality $k$ if (i) clearing the land for production yields a positive income, i.e., $V_{i k t}^{d}>0$; and (ii) income from moving and producing in municipality $k$ is greater than that of producing in municipality $j$, that is, $V_{i k t}^{d}-\phi\left(d_{k, j}\right)>V_{i j t}^{d}$, which results in 


$$
d_{i k t}=1\left[V_{i k t}^{d}>0\right] \times 1\left[V_{i k t}^{d}-V_{i j t}^{d}>\phi\left(d_{k, j}\right)\right],
$$

that can also be written as

$$
d_{i k t}=1\left[V_{i k t}^{d}>0\right] \times\left\{1-1\left[V_{i k t}^{d}-V_{i j t}^{d} \leq \phi\left(d_{k, j}\right)\right]\right\} .
$$

If we assume that condition (3.5) is valid, that is, if

$$
L_{i k t}=L_{i j t}=L_{t}\left(Q_{i}\right)=L_{i t},
$$

then equation (3.4) can be written as

$$
\left(1-p_{i k t}^{e}\right) V_{i k t}^{c}-p_{i k t}^{e} L_{i t}-\phi\left(d_{k, j}\right)>\left(1-p_{i j t}^{e}\right) V_{i j t}^{c}-p_{i j t}^{e} L_{i t}
$$

or

$$
\underbrace{\left(1-p_{i k t}^{e}\right) V_{k j t}^{c}-\left(1-p_{i j t}^{e}\right) V_{i j t}^{c}}_{\text {Expected gain difference if not punished }}-\underbrace{\left(p_{i k t}^{e}-p_{i j t}^{e}\right) L_{i t}}_{\text {Expected loss difference if punished }}>\phi\left(d_{k, j}\right)
$$

Then, equations (8.1) and (8.2) can be written, respectively, as

$$
\begin{array}{ccc}
d_{i j t}=1\left[\left(1-p_{i j t}^{e}\right) V_{i j t}^{c}>p_{i j t}^{e} L_{i t}\right] & \times 1\left[\left(1-p_{i k t}^{e}\right) V_{i k t}^{c}-\left(1-p_{i j t}^{e}\right) V_{i j t}^{c}-\left(p_{i k t}^{e}-p_{i j t}^{e}\right) L_{i t} \leq \phi\left(d_{k, j}\right)\right] \\
d_{i k t}=1\left[\left(1-p_{i k t}^{e}\right) V_{i k t}^{c}>p_{i k t}^{e} L_{i t}\right] & \times \quad\left\{1-1\left[\left(1-p_{i k t}^{e}\right) V_{i k t}^{c}-\left(1-p_{i j t}^{e}\right) V_{i j t}^{c}-\left(p_{i k t}^{e}-p_{i j t}^{e}\right) L_{i t} \leq \phi\left(d_{k, j}\right)\right]\right\}
\end{array}
$$

If we now add assumption (3.6),

$$
V_{i j t}^{c}=V_{i k t}^{c}=V_{t}^{c}\left(Q_{i}, Z\right)=V_{i t}^{c},
$$


then condition (3.4) becomes

$$
\left(1-p_{i k t}^{e}\right) V_{i t}^{c}-p_{i k t}^{e} L_{i t}-\phi\left(d_{k, j}\right)>\left(1-p_{i j t}^{e}\right) V_{i t}^{c}-p_{i j t}^{e} L_{i t} .
$$

Rearranging the variables results in

$$
\begin{array}{r}
\left(1-p_{i k t}^{e}\right) V_{i t}^{c}-\left(1-p_{i j t}^{e}\right) V_{i t}^{c}-\left(p_{i k t}^{e}-p_{i j t}^{e}\right) L_{i t}>\phi\left(d_{k, t}\right) \\
\left(1-p_{i k t}^{e}-1+p_{i j t}^{e}\right) V_{i t}^{c}-\left(p_{i k t}^{e}-p_{i j t}^{e}\right) L_{i t}>\phi\left(d_{k, t}\right) \\
\left(p_{i j t}^{e}-p_{i k t}^{e}\right) V_{i t}^{c}-\left(p_{i k t}^{e}-p_{i j t}^{e}\right) L_{i t}>\phi\left(d_{k, t}\right)
\end{array}
$$

and, finally, in condition (3.7),

$$
\left(p_{i j t}^{e}-p_{i k t}^{e}\right)\left[V_{i t}^{c}+L_{i t}\right]>\phi\left(d_{k, t}\right)
$$

which takes us back to conditions (3.8) and (3.9):

$$
\begin{aligned}
d_{i j t}=1\left[\left(1-p_{i j t}^{e}\right) V_{i t}^{c}>p_{i j t}^{e} L_{i j t}\right] & \times 1\left[\left(p_{i j t}^{e}-p_{i k t}^{e}\right)\left(V_{i t}^{c}+L_{i t}\right) \leq \phi\left(d_{k, j}\right)\right] \\
d_{i k t}=1\left[\left(1-p_{i k t}^{e}\right) V_{i t}^{c}>p_{i k t}^{e} L_{i j t}\right] & \times\left\{1-1\left[\left(p_{i j t}^{e}-p_{i k t}^{e}\right)\left(V_{i t}^{c}+L_{i t}\right) \leq \phi\left(d_{k, j}\right)\right]\right\} .
\end{aligned}
$$





\section{Appendix IV}

Table 12 - Effect of listing on agricultural credit

\begin{tabular}{lccc}
\hline \hline & \multicolumn{3}{c}{ Dependent variable: } \\
\cline { 2 - 4 } & \multicolumn{3}{c}{ Agricultural credit } \\
& $(1)$ & $(2)$ & $(3)$ \\
\hline Treated & 0.105 & -0.355 & $-1.526^{* *}$ \\
& $(0.363)$ & $(0.445)$ & $(0.625)$ \\
& & & \\
PIB $_{t-1}$ & & & $0.0002^{* *}$ \\
& & & $(0.0001)$ \\
\hline State fixed effect & No & Yes & Yes \\
Year fixed effects & Yes & Yes & Yes \\
Observations & 5,900 & 5,900 & 3,905 \\
Adjusted R $\mathrm{R}^{2}$ & 0.008 & 0.135 & 0.470 \\
F Statistic & $6.595^{* * *}$ & $55.199^{* * *}$ & $193.051^{* * *}$ \\
\hline \hline
\end{tabular}

Notes: Standard errors clustered by state. PIB is in 1999 BRL. ${ }^{*} \mathrm{p}<0.1 ;{ }^{* *} \mathrm{p}<0.05 ;{ }^{* * *} \mathrm{p}<0.01$.

Table 13 - Effect of listing on credit for cattle raising

\begin{tabular}{lccc}
\hline \hline & \multicolumn{3}{c}{ Dependent variable: } \\
\cline { 2 - 4 } & \multicolumn{3}{c}{ Credit for cattle raising } \\
& $(1)$ & $(2)$ & $(3)$ \\
\hline Treated & $1.538^{* * *}$ & $1.295^{* * *}$ & $1.216^{* *}$ \\
& $(0.434)$ & $(0.414)$ & $(0.506)$ \\
& & & $0.00004^{* * *}$ \\
PIB $_{t-1}$ & & & $(0.00002)$ \\
& & & \\
\hline State fixed effects & No & Yes & Yes \\
Year fixed effects & Yes & Yes & Yes \\
Observations & 5,910 & 5,910 & 3,906 \\
Adjusted $\mathrm{R}^{2}$ & 0.087 & 0.219 & 0.308 \\
F Statistic & $63.584^{* * *}$ & $98.512^{* * *}$ & $97.658^{* * *}$ \\
\hline \hline
\end{tabular}

Notes: Standard errors clustered by state. PIB is in 1999 BRL. ${ }^{*} \mathrm{p}<0.1 ;{ }^{* *} \mathrm{p}<0.05 ;{ }^{* * *} \mathrm{p}<0.01$. 
Table 14 - Effect of listing on total credit

\begin{tabular}{lccc}
\hline \hline & \multicolumn{3}{c}{ Dependent variable: } \\
\cline { 2 - 4 } & \multicolumn{3}{c}{ Total credit } \\
& $(1)$ & $(2)$ & $(3)$ \\
\hline Treated & $1.607^{* * *}$ & $0.913^{* * *}$ & -0.311 \\
& $(0.423)$ & $(0.292)$ & $(0.853)$ \\
& & & $0.0002^{* * *}$ \\
PIB $_{t-1}$ & & & $(0.0001)$ \\
& & & Yes \\
\hline State fixed effects & No & Yes & Yes \\
Year fixed effects & Yes & 5,881 & 3,886 \\
Observations & 5,881 & 0.212 & 0.592 \\
Adjusted ${ }^{2}$ & 0.033 & $93.795^{* * *}$ & $313.829^{* * *}$ \\
F Statistic & $22.978^{* * *}$ &
\end{tabular}

Notes: Standard errors clustered by state. PIB is in 1999 BRL. ${ }^{*} \mathrm{p}<0.1 ;{ }^{* *} \mathrm{p}<0.05 ;{ }^{* * *} \mathrm{p}<0.01$. 
Appendix V - Group composition 


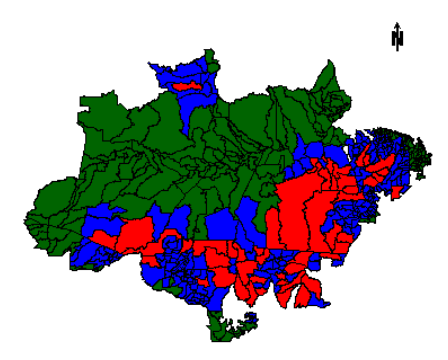

- Non-listed with no listed neighbours
- Non-listed with listed neighbours

\begin{tabular}{llll} 
- Non-listed with listed neighbours & & 1 & 1 \\
\hline & 500 & $1000 \mathrm{~km}$
\end{tabular}

(a) Inverse distance criterion, maximum distance: 2.1

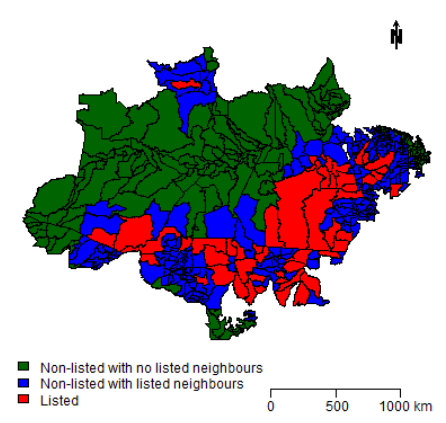

(c) Inverse distance criterion, maximum distance: 2.3

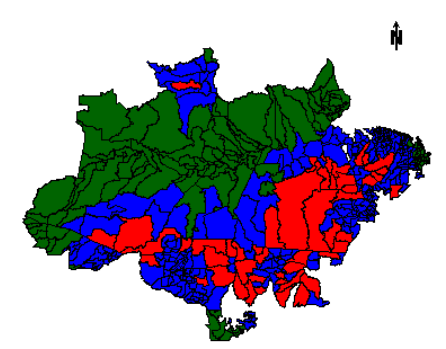

E- Non-listed with no listed neighbours

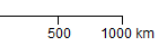

(e) Inverse distance criterion, maximum distance: 2.5

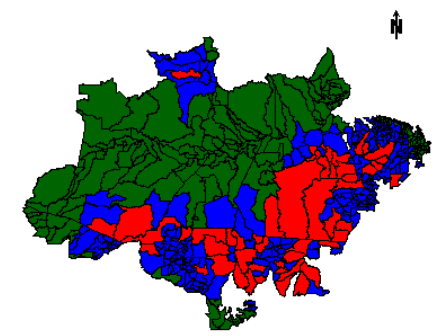

- Non-listed with no listed neighbours
Non-listed with listed neighbours
Listed

(b) Inverse distance criterion, maximum distance: 2.2
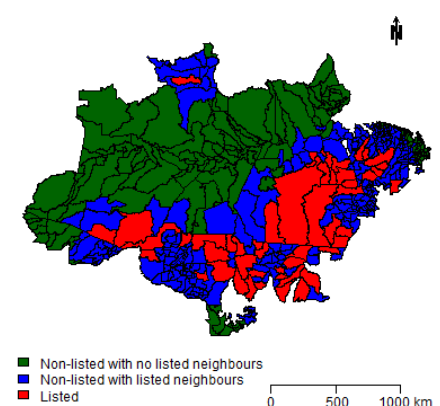

(d) Inverse distance criterion, maximum distance: 2.4

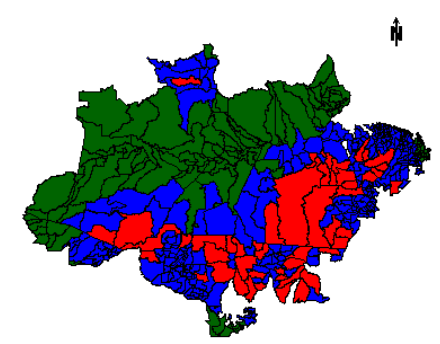

- Non-listed with no listed neighbours

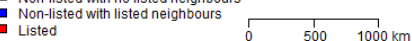

(f) Inverse distance criterion, maximum distance: 2.6

Figure 9 - Control and treatment groups under different neighbourhood criteria 


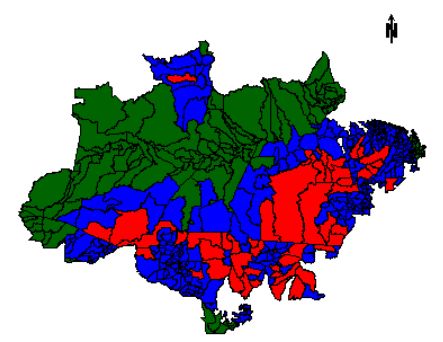

- Non-listed with no listed neighbours - Non-lis

(a) Inverse distance criterion, maximum distance: 2.7

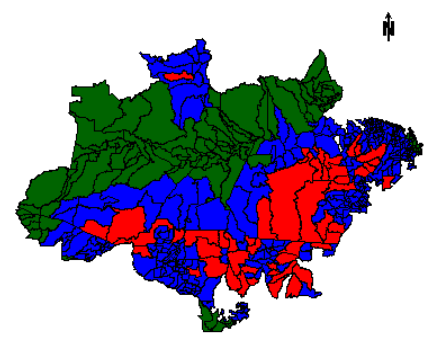

- Non-listed with no listed neighbours - Non-lis

(c) Inverse distance criterion, maximum distance: 2.9

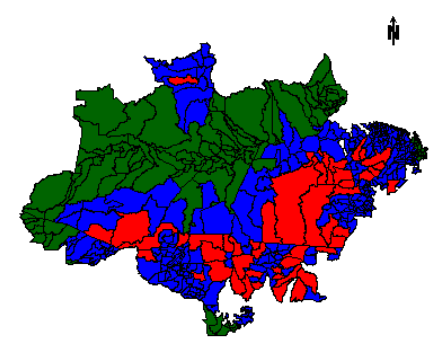

- Non-listed with no listed neighbours - Listed

(b) Inverse distance criterion, maximum distance: 2.8

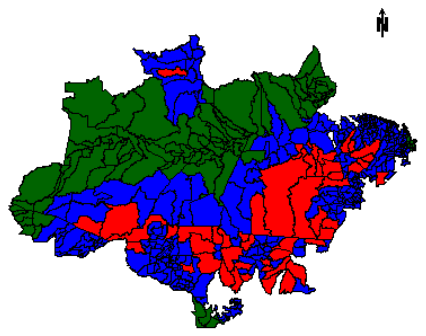

- Non-listed with no listed neighbour Non-listed with listed neighbours
Listed

(d) Inverse distance criterion, maximum distance: 3

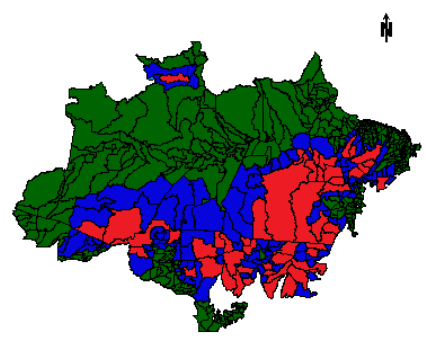

ㅁ Blacklisted
․ Treatment
Control

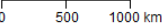

(e) Queen contiguity criterion

Figure 10 - Control and treatment groups under different neighbourhood criteria 